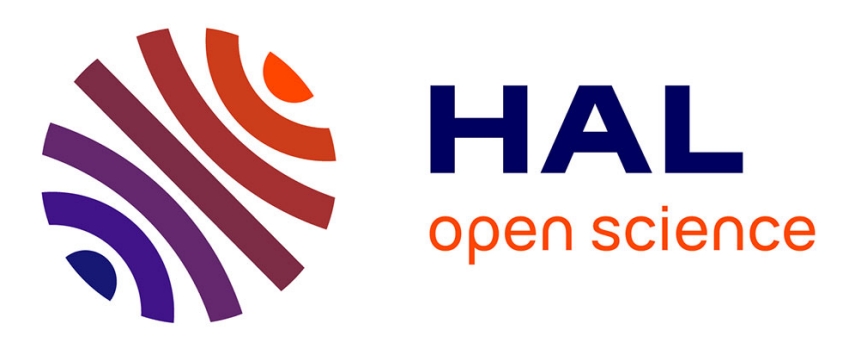

\title{
Influence of root exudation of white lupine (Lupinus albus L.) on uranium phytoavailability in a naturally uranium-rich soil
}

Pascale Henner, Félix Bredoire, Antoine Tailliez, Frederic Coppin, Sylvie

Pierrisnard, Virginie Camilleri, Catherine Keller

\section{To cite this version:}

Pascale Henner, Félix Bredoire, Antoine Tailliez, Frederic Coppin, Sylvie Pierrisnard, et al.. Influence of root exudation of white lupine (Lupinus albus L.) on uranium phytoavailability in a naturally uranium-rich soil. Journal of Environmental Radioactivity, 2018, 190-191, pp.39-50. 10.1016/j.jenvrad.2018.04.022 . hal-01822147

\section{HAL Id: hal-01822147 \\ https://hal.science/hal-01822147}

Submitted on 23 Jun 2018

HAL is a multi-disciplinary open access archive for the deposit and dissemination of scientific research documents, whether they are published or not. The documents may come from teaching and research institutions in France or abroad, or from public or private research centers.
L'archive ouverte pluridisciplinaire HAL, est destinée au dépôt et à la diffusion de documents scientifiques de niveau recherche, publiés ou non, émanant des établissements d'enseignement et de recherche français ou étrangers, des laboratoires publics ou privés. 
1 Influence of root exudation of white lupine (Lupinus albus L.) on uranium

2 phytoavailability in a naturally uranium-rich soil

3

4 Pascale Henner $^{1 *}$, Félix Brédoire ${ }^{1}$, Antoine Tailliez ${ }^{1}$, Frédéric Coppin ${ }^{1}$, Sylvie Pierrisnard ${ }^{1}$,

$5 \quad$ Virginie Camilleri ${ }^{2}$, Catherine Keller ${ }^{3}$

6

$7 \quad{ }^{1}$ Institute for Radioprotection and Nuclear Safety (IRSN/PSE-ENV/SRTE), Laboratory of

8 research on radionuclides transfer within terrestrial ecosystems (LR2T), Cadarache, Bat 183,

9 BP 3, 13115 Saint Paul-lez-Durance, France

$10{ }^{2}$ Institute for Radioprotection and Nuclear Safety (IRSN/PSE-ENV/SRTE), Laboratory of

11 research on radionuclides effects on ecosystems (LECO), Cadarache, Bat 183, BP 3, 13115

12 Saint Paul-lez-Durance, France

$13{ }^{3}$ Aix Marseille Univ, CNRS, IRD, INRA, Coll France, CEREGE, BP 80, 13545 Aix-en-

14 Provence cedex 04, France

15

16

$17 *$ Corresponding author

18 Tel. : +33(0)442199561

$19 \quad$ Fax : +33(0)442199151

20 E-mail address: pascale.henner@irsn.fr

21

22

23

24

25 
26 - Rhizotest study with contrasted P offer tested citrate effect on U phytoavailability

27 - Small (0.4\% total U) but easily accessible U pool in the tested natural U-rich soil

28 - Accessible U pool in soil was not significantly affected by $\mathrm{P}$ or citrate concentration

29 - U translocation to shoots, but not global uptake, was related to lupine exudation rate

30 - Lupine plants extracted $25-40 \%$ of the estimated $U$ available pool in 5 days

31

32

33 


\section{Abstract}

35 Mechanisms of uranium (U) transfer from soil to plants remain poorly understood. The 36 kinetics of supply of $U$ to the soil solution from solid phases could be a key point to 37 understand its phytoavailability and implications for environmental risk assessment. Root 38 activity, particularly the continuous release of organic acids in the rhizosphere, could have an 39 effect on this supply. We tested the impact of citrate exudation by roots of Lupinus albus, 40 either $\mathrm{P}$-sufficient $(\mathrm{P}+)$ or $\mathrm{P}$-deficient $(\mathrm{P}-)$, on the phytoavailability of $\mathrm{U}$ from a naturally contaminated soil (total content of $413 \mathrm{mg} \mathrm{U} \mathrm{kg}^{-1}$ ) using a rhizotest design. Combined effects of $\mathrm{P}$ (P-/P+ used to modulate plant physiology) and citrate (model exudate) on the

\section{Key-words}

$57 \quad$ Lupinus albus L.

58 Natural U-rich soil 
59 Rhizotest

60 Batch extraction

61 Exudation

62 Uptake

63

64 
66 Uranium is an ubiquitous radioactive metal with an average soil concentration of $3 \mathrm{mg} \mathrm{kg}^{-1}$.

67 Due to anthropogenic activities, $U$ concentrations in soils can reach locally several hundreds

68 of $\mathrm{mg} \mathrm{U} \mathrm{kg}^{-1}$, which may result in contamination of soil and water resources (Ribera et al., 69 1996; Bourrelier and Berthelin, 1998; Ragnarsdottir and Charlet, 2000). The different U70 mining operations (drilling, ore processing, on site-storage on tailings, post-mining 71 operations) have resulted in areas where the environment may be contaminated by $\mathrm{U}$ (Pfeifer 72 et al., 1994) and other metals (e.g. Ba, frequently used in exhaust water treatment). Phosphate 73 rocks used as fertilizers in agriculture are also a source of $U$ (among other metals) in 74 cultivated soils: concentrations in phosphate fertilizer can reach several hundreds of mg $\mathrm{U} \mathrm{kg}^{-}$ $75^{1}$ (Romero Guzman et al., 2002), with application of several hundred kg fertilizer per ha and 76 per year.

77 Uranium has no physiological role in plant. Root uptake and translocation to shoots are very 78 variable and result in Transfer Factors ( $\mathrm{Bq} \mathrm{U} \mathrm{kg}^{-1}$ dry weight shoots $/ \mathrm{Bq} \mathrm{U} \mathrm{kg}^{-1}$ soil) from $10^{-5}$ to $10^{-2}$ 79 (IAEA, 2010). In plant, $\mathrm{U}$ is mainly associated to roots, with concentrations as high as $10^{2} \mathrm{mg}$ $80 \mathrm{U} \mathrm{kg}^{-1}$ d.w. roots (Dushenkov et al., 1997; Tailliez et al., 2013). Phytotoxic effects have been 81 recorded on growth and development (Sheppard et al., 1992; Straczek et al., 2009), 82 chlorophyll content (Aery and Jain, 1997) and, oxidative stress (Vandenhove et al., 2006a, 83 Vanhoudt et al., 2008). Uranium also affects the plants indirectly through interferences with 84 phosphate (Misson et al., 2009) or iron (Viehweger and Geipel, 2010; Doustaly et al., 2014) 85 homeostasis. Despite all these data, it is still difficult to clearly establish dose-response 86 relationships between the concentration of $U$ in soil (or soil solution), the concentration or 87 distribution of $U$ in plants, and their induced phytotoxicity (Sheppard et al., 2005). Indeed, 88 depending on the study, toxic effects on plants have been recorded for total concentrations of $89 \mathrm{U}$ in soil that range from background levels (a few $\mathrm{mg} \mathrm{U} \mathrm{kg}^{-1}$ soil) up to several hundred $\mathrm{mg} \mathrm{U}$ 
$90 \mathrm{~kg}^{-1}$ soil (Sheppard et al., 1992), even thousands of $\mathrm{mg} \mathrm{U} \mathrm{kg}^{-1}$ soil (Meyer and McLendon, 1997;

91 Stojanovic et al., 2009). These discrepancies may hardly be related to parameters like plant species or toxicity range, but may rather be related to the environmental bioavailability and phytoavailability of $\mathrm{U}$. Parameters responsible for $\mathrm{U}$ phytoavailability in soils are not well

94 understood despite the large literature available on $U$ behaviour in soils (e.g. Ragnarsdottir and Charlet, 2000). Indeed, way(s) by which U enters the root and moves in the plant are still unidentified. In addition, studies in which speciation of $U$ in solution or soil solution had been explicitly considered have shown that several $U$ species other than the free uranyl ion had to be taken into account to correctly predict its transfer to plants (Ebbs et al., 1998; Vandenhove et al., 2006b, Laroche, 2005; Mihalik et al., 2012). These studies allowed to hypothesize that rhizospheric processes (processes at the soil/root interface, as defined by Hinsinger, 1998 or Hinsinger et al. 2005), such as uptake and exudation, may drive the U phytoavailability. Physico-chemical conditions in the rhizospheric soil may differ considerably from those of the bulk soil because of root activities involving notably exudation processes. Variation of rhizospheric $\mathrm{pH}$ and/or exudation of complexing agents (e.g. citrate), allow plants to stimulate desorption of nutrients (e.g. Fe, P) from the soil solid phase, increases their solubility in soil solution and subsequently their uptake and translocation (Duffner et al., 2012; Röhmeld, 1987; Vance et al., 2003; Briat, 2008). Citrate is continuously exuded by plant roots when plants are experiencing Fe or P starvation (Kahm et al., 1999; Hinsinger, 2001). However, organic acids are also good chelators for $\mathrm{U}$, and they have been efficiently used in amendment-assisted phytoremediation studies of U-contaminated soils (Huang et al. 1998; Duquène et al., 2008; Mihalik et al., 2012), although it has been argued that its efficiency might be limited because of the large amount needed and its quick biodegradability (Jones, 1998). It has been stated that citrate-U complexes may be available in the rhizosphere through release of uranyl ion and/or uptake of complexes, which may also be the/one of the plant 
115 circulation forms allowing for enhanced translocation (Laurette et al., 2012a, b). In soils, U is

116 frequently associated with P and Fe carrying phases (Pfeifer et al., 1994; Payne et al., 1996;

117 Fuller et al., 2002; Raicevic et al., 2006). Thus, during root exudation of protons or organic

118 acids to increase $\mathrm{P}$ and Fe desorption from the solid phase (Hinsinger, 1998; McLaughlin et

119 al., 1998; Kahm et al., 1999), U concentration may also increase in the rhizosphere. Finally,

120 the phytoavailability of $U$ may depend on the concomitant behaviour of the released elements,

121 whether they are absorbed by roots, as free ion or complexes, or are subjected to precipitation,

122 coprecipitation or resorption processes onto the soil solid phase.

123 The objective of this study was to evaluate if exudation of a model organic acid, namely

124 citrate, may participate in maintaining a high $U$ phytoavailability in soil solution. An

125 experiment was performed with a modified RHIZOtest ${ }^{\circledR}$ (Bravin et al., 2010), used with

126 naturally U-rich soils and white lupine plants (Lupinus albus). Plants were either P-starved or

127 P-sufficient during the pre-culture period prior to soil exposure, to induce two different levels

128 of citrate exudation. Uranium accumulated in roots and shoots were assessed with respect to

129 citrate exudation level. We used white lupine because it is a model plant for P study, which

130 induces proteoïd roots exudating a high level of organic acids when P-starved (Keerthisinghe

131 et al., 1998; Tailliez et al., 2013). To gain more insights on the dynamics of $U$ at the soil/soil

132 solution interface in relation with $\mathrm{P}$ and citrate levels, batch dynamic desorption experiments

133 were also conducted.

134

135 2. Material and Methods

136 2.1. U-contaminated soils

137 The tested soil was sampled in the vicinity of one of the most U-concentrated pitchblende

138 veins existing in Europe, on the site of La Creuzaz/Les Marécottes, $7 \mathrm{~km}$ West from Martigny,

139 Switzerland. This site has been described by Pfeifer et al. (1994). It was characterized by an 
140

141

142

143

144

145

146

147

148

149

150

151

152

153

154

155

156

157

158

159

160

161

162

163

on site radioactivity measurement (CoMo 170 analyser (Saphymo, France), $15 \mathrm{~cm}$ from the soil surface). The top soil (A horizon, 0-15 cm following removal of the OL horizon) was sampled, homogenized, dried at room temperature and sieved at 2-mm mesh size before use. Soil properties (accredited analysis; INRA, LAS, Arras, France) and soluble U (ICP-AES, see 2.4.3.3) analysis are displayed in Table 1. The soil is classified as Colluviosol (RP, 2008). It is characterized by an acidic $\mathrm{pH}$ and a high total $\mathrm{U}$ content of around $400 \mathrm{mg} \mathrm{kg}^{-1}$. The available $\mathrm{P}$ content (P Olsen) is rather low as related to agricultural standards.

During the study, 3 other soils were collected at different distances from the pechblende vein, in order to get a naturally-produced U gradient in the "same" soil, among which 2 were chosen. A second soil (soil 2) had similar properties but a higher U content (500 mg U kg ${ }^{-1}$ soil) and was situated downwards soil 1 although the gradient was supposed to be related to distance from the vein. This could have signed a peculiar behavior regarding speciation, migration or (bio) availability. Thus, the complete experimental set up described for soil 1 was applied to soil 2. Results were equivalent to those of soil 1 are thus not detailed in the text but can be seen in supplementary S4.

\subsection{Plant species}

Seeds of white lupine (Lupinus albus L., cv. Amiga) were provided by S.A.S. FlorimondDesprez (Cappelle en Pévèle, France). The seed lot was treated by Wakil XL (Syngenta Agro S.A.S., Guyancourt, France) before use to prevent the post-germination development of diseases. Seeds were calibrated at $300 \pm 20 \mathrm{mg}$ before use to guarantee a homogeneous initial development of the seedlings. Seeds were surface sterilized using a four-step protocol as described in Tailliez et al. (2013). They were re-moistened in ultrapure water for $24 \mathrm{~h}$ at $24^{\circ} \mathrm{C}$ in the dark in order to homogenize and synchronize their germination. 
166 2.3.1. Nutrient solutions

167 The nutrient solution composition was identical to previous hydroponic studies (Tailliez et al.,

168 2013). The basic composition was: $2 \mathrm{mM} \mathrm{Ca}\left(\mathrm{NO}_{3}\right)_{2}, 0.7 \mathrm{mM} \mathrm{K}_{2} \mathrm{SO}_{4}, 0.5 \mathrm{mM} \mathrm{MgSO}_{4} .7 \mathrm{H}_{2} \mathrm{O}$, $1690.1 \mathrm{mM} \mathrm{KCl}, 20 \mu \mathrm{M}$ Fe(III)-EDTA, $10 \mu \mathrm{M} \mathrm{H}_{3} \mathrm{BO}_{3}, 0.5 \mu \mathrm{M} \mathrm{MnSO}_{4} \cdot \mathrm{H}_{2} \mathrm{O}, 0.5 \mu \mathrm{M} \mathrm{ZnSO}_{4}$. $1707 \mathrm{H}_{2} \mathrm{O}, 0.2 \mu \mathrm{M} \mathrm{CuSO}_{4} \cdot 5 \mathrm{H}_{2} \mathrm{O}, 0.01 \mu \mathrm{M}\left(\mathrm{NH}_{4}\right)_{6} \mathrm{Mo}_{7} \mathrm{O}_{24} \cdot 4 \mathrm{H}_{2} \mathrm{O}$. Phosphorus was supplied as $171100 \mu \mathrm{M}$ (P-sufficient condition for plant physiology, labelled $\mathrm{P}+$ in the document) or $1 \mu \mathrm{M}$ 172 (P-deficient condition labelled $\mathrm{P}$ - in the document) $\mathrm{KH}_{2} \mathrm{PO}_{4}$. No $\mathrm{pH}$ regulation was used as it 173 would have interfered with the lupine roots physiology regarding P status.

174

175 2.3.2. Solution for root exudate collection

176 For root exudate collection, a specifically-designed solution was used (Horst W., personal 177 communication, 2011) to ensure the integrity of the biological membranes while not 178 interfering with further organic acids analysis. Its composition was: $0.25 \mathrm{mM} \mathrm{CaSO}_{4}, 10 \mu \mathrm{M}$ $179 \mathrm{H}_{3} \mathrm{BO}_{3}, 0.5 \mu \mathrm{MnSO}_{4} \cdot \mathrm{H}_{2} \mathrm{O}, 0.5 \mu \mathrm{M} \mathrm{ZnSO}_{4} \cdot 7 \mathrm{H}_{2} \mathrm{O}, 0.2 \mu \mathrm{M} \mathrm{CuSO}_{4} \cdot 5 \mathrm{H}_{2} \mathrm{O}$ and $0.01 \mu \mathrm{M}$ $180 \quad\left(\mathrm{NH}_{4}\right)_{6} \mathrm{Mo}_{7} \mathrm{O}_{24} \cdot 4 \mathrm{H}_{2} \mathrm{O}$.

181

182 2.4. Study of U phytoavailability in the rhizotest device

183 Lupine plants were grown and exposed to soil in a specifically designed device similar to the 184 RHIZOtest $^{\circledR}$ described in detail in Chaignon and Hinsinger (2003) and Bravin et al. (2010) 185 (Figure 1). This device is composed of 2 parts, the upper one, closed at its basis by a 30- $\mu \mathrm{m}$ 186 nylon mesh membrane, on which plant roots develop a root mat during the preculture step, 187 and the bottom one, receiving the soil layer. Both are put into close contact during the 188 exposure step. In this device, sampling of soils and roots is facilitated by their physical 
separation by the membrane, which does not result in a chemical separation. Thus, uptake and

190 exudation processes are preserved.

191 Some of the experimental parameters (duration of culture, solution composition) were chosen

192 so as to match the conditions used in Tailliez et al. (2013). They aimed at obtaining lupine 193 plants in the desired physiology state (P-sufficient vs P-deficient) as piloted by P-level in 194 solution, and discriminated by their level of citrate exudation.

195 Figure 2 resumed the experimental set-up. Test of soil 2 only add to this set-up rhizotests 196 devoted to soil exposure (5 upper parts with plants and 5 bottom parts with soil per P 197 condition), the controls being common (supplementary material S4). These were conducted as 198 those with soil 1.

200 2.4.1. Preculture step in hydroponics

201 Plants were grown on the upper part of the rhizotest from seeds. Preliminary experiments 202 allowed optimizing rhizotest device parameters (number of seeds, duration of pre-culture 203 step) to get an appropriate root mat for exposure to soil, a prerequisite for the use of this 204 device. Six sterilized and re-imbibed seeds were sown on each rhizotest device. Thirty 205 devices (each containing 6 plants) were prepared (10 devices dedicated to soil exposure, 10 206 devices for growth and hydroponic control and 10 extra devices to ensure a sufficient number 207 of healthy and homogeneous devices at the end of pre-culture). Devices were disposed in two 208 tanks containing nutrient solutions (15 devices in $\mathrm{P}$ - and 15 devices in $\mathrm{P}+$ ) continuously 209 aerated and renewed every week. The whole dispositive was kept in a growth box under 210 controlled conditions: $16 \mathrm{~h} / 8 \mathrm{~h}$ light/night cycle, $26 / 20 \pm 1^{\circ} \mathrm{C}$ day/night temperature, $60 \pm 5 \%$ 211 relative air humidity and light intensity of $150 \mu \mathrm{mol} \mathrm{m}^{-2} \mathrm{~s}^{-1}$. Seedlings were grown in 212 hydroponics in $\mathrm{P}+$ or $\mathrm{P}-$ nutrient solutions for 38 days, which was the delay to get a 213 homogeneous root mat. Due to the constraint within the root mat, less proteoïd roots were 
214 observed in rhizotests in $\mathrm{P}$ - conditions than in free-roots experiment described in Tailliez et al.

215 (2013), and some also appeared in $\mathrm{P}+$ conditions. Yet analysis of organic acids exudation 216 showed that conditions were adequate to obtained two different levels of exudation with that 217 in $\mathrm{P}$ - being higher than in $\mathrm{P}+$.

218

219 2.4.2. Exposure to soil

220 Twenty rhizotest devices were prepared. Each bottom part was filled with a 2-mm-thick soil 221 layer, corresponding to $20 \mathrm{~g}$ of dry soil. Bottom parts were connected to $0.5 \mathrm{dm}^{3} \operatorname{tanks}$ 222 containing $50 \mathrm{~mL}$ of nutrient solution, $\mathrm{P}-\mathrm{or} \mathrm{P}+$, each with 10 replicates. First, the bottom 223 parts were incubated in the dark for 1 week, until the soil was homogenously equilibrated 224 with the solution. The resultant soil humidity was around $20 \%$, close to half-saturation. Half 225 of the rhizotest devices were kept bare as non rhizospheric controls and half received their 226 corresponding upper parts with lupine plants. Among the 20 pre-cultured upper parts per P 227 condition, 5 were randomly chosen to be displayed on soil. Exposure was conducted for 5 228 days. During pre-incubation and exposure, the nutrient solution was renewed each day.

229 For each $\mathrm{P}$ condition, 5 of the 15 upper parts launched in the pre-culture steps (previously 230 qualified as "growth and hydroponic control") were also randomly chosen. They were kept in 231 hydroponics for 5 more days, in the same conditions than the rhizotests with soil (individual 232 pot).

234 2.4.3. Sampling and measures

235 2.4.3.1. Growth of lupine plants

236 The growth of plants during the pre-culture step was evaluated by weekly counting the 237 number of developed leaves. 
238 Biomass (fresh and dry -after drying in a ventilated hood at $60^{\circ} \mathrm{C}$ until constant weight) of

239 aerial parts and roots were measured: at the end of the pre-culture step on the extra rhizotests 240 that were as healthy as the others ( $\mathrm{n}=5$ per $\mathrm{P}$ condition) and at the end of exposure, both on 241 soil rhizotests ( $\mathrm{n}=5$ per $\mathrm{P}$ condition) and on "hydroponic control" rhizotests ( $\mathrm{n}=5$ per $\mathrm{P}$ 242 condition).

243 Biomasses were around 0.5 and $1.9 \mathrm{~g}_{\text {d.w. }}$ rhizotest $^{-1}$ respectively for roots and shoots, whatever 244 the conditions (details in Figure S1, supplementary material). Only a slight increase of 245 biomass was recorded during the exposure phase. Biomasses were similar for both $\mathrm{P}$ 246 conditions, ensuring that differences between $\mathrm{P}+$ and $\mathrm{P}$ - rhizotests will not be related to 247 differences in biomasses, but to other physiological differences resulting from P availability.

248 Periodic photography of the root mat allowed determining the appropriate time to start the 249 exposure that is when the mesh surface was covered with roots. The volume of the nutrient 250 solutions underneath the rhizotests was followed by periodic weighing, and evaporation was 251 compensated by addition of new solution.

253 2.4.3.2. Exudation of organic acids: collection and analysis

254 Quantification of root mat exudation was conducted at the end of the pre-culture period on all 255 rhizostests (per P condition, the 5 exposed rhizotests before application on soil layer, the 5 256 extra rhizotests and the 5 hydroponic control rhizotests) and after exposure to soil or 257 hydroponic solution as described in Tailliez et al. (2013), with specific adaptation to the root 258 mats of the rhizotest. Roots were first rinsed in deionised water, then submerged for $3 \mathrm{~h}$ into $259100 \mathrm{~mL}$ of the root exudate collection solution.

260 Aliquots of $10 \mathrm{~mL}$ root exudates solutions were filtered on a $0.2 \mu \mathrm{m}$ sterile filter 261 (polyethersulfone, VWR) and kept frozen at $-20^{\circ} \mathrm{C}$ after addition of $10^{-4} \mathrm{M} \mathrm{NaN}$ for 262 preservation until analysis. Aliquots were then evaporated to dryness with freeze 
263 drying/vacuum concentration (SpeedVac, Jouan, Paris, France). Residues were dissolved in

$264150 \mu \mathrm{L}$ deionised water and analysed for citrate and other organic acids with Ionic Liquid

265 Chromatography (ILC, Dionex autosampler ICS 3000, AS 11 HC column, eluent KOH (1-45

$266 \mathrm{mM}$, flow rate: $1 \mathrm{~mL} \mathrm{~min}^{-1}$ ), suppressor ASRS $4 \mathrm{~mm}$, detection by conductivity, injection

267 volume: $100 \mu \mathrm{L}$, quantification quantification limit: $10 \mu \mathrm{g} \mathrm{L} \mathrm{L}^{-1}$ ). Despite several optimizing

268 operations, it was not possible to separate correctly malate and succinate, thus only citrate,

269 oxalate, formate, lactate and acetate acids were quantified.

270

271 2.4.3.3. Analysis of root and shoot $U$ content

272 Dry biomass of roots and shoots were digested $\left(65 \% \mathrm{HNO}_{3}\right.$ and $\left.30 \% \mathrm{H}_{2} \mathrm{O}_{2}, 120^{\circ} \mathrm{C}\right)$, then 273 evaporated to dryness and redissolved in $10 \mathrm{~mL} 2 \% \mathrm{v}: \mathrm{v} \mathrm{HNO}_{3}$ before analysis. Uranium and 274 major cation contents were analysed by Inductively Coupled Plasma-Atomic Emission 275 Spectrometry (ICP-AES, OPTIMA 4300 DV, Perkin Elmer, quantification limit $=10 \mu \mathrm{g} \mathrm{L}^{-1}$ 276 for each element) or Inductively Coupled Plasma-Mass Spectrometry (ICP-MS, Agilent

277 7500Cs, detection limit $=10 \mathrm{ng} \mathrm{L}^{-1}$ ) depending on their concentration (as related to tissue type 278 and exposure condition).

279 Despite their highest purity grade, some salts, phosphate salts mainly, contained small 280 amounts of $U$ as impurity (< q.1. in nutrient solution). Final $U$ concentrations measured in 281 plants were corrected for this background, subtracting $U$ concentrations measured in the 282 controls $(38 d+5 d$ without soil exposure).

284 2.5. Batch study of U behaviour in natural U-contaminated soils

285 2.5.1. Calculation of citrate concentrations

286 Batch studies were used so as to be the "chemical" equivalent of a rhizotest. The chosen 287 citrate concentrations in the solution were representative of those that could be present at the 
288 soil/root interface in the rhizotest for the different conditions used (P level). We used the

289 maximal values of citric acid exudation rates reported in hydroponics (Tailliez et al., 2013), 290 that is $400 \mu \mathrm{mol}_{\text {Cit }} \mathrm{kg}^{-1}$ d.w. root $\mathrm{h}^{-1}$ in $\mathrm{P}-\mathrm{U}-$ condition and $100 \mu \mathrm{mol}_{\text {Cit }} \mathrm{kg}^{-1}$ d.w. root $\mathrm{h}^{-1}$ in $\mathrm{P}+\mathrm{U}+$

291 condition. These values were used to calculate the corresponding quantity of citrate exuded 292 per rhizotest (root mass from 6 plants, in contact with $20 \mathrm{~g}$ soil, for 5 days), corrected for the 293 different soil saturation state in the batch system (4 $\mathrm{g}$ soil, $\mathrm{V} / \mathrm{m}$ ratio) compared to the 294 rhizotest. The corresponding tested concentrations in the batch system solutions were 10.15 295 and $40.6 \mathrm{mg} \mathrm{L}^{-1}$ citric acid, respectively for the P-sufficient and the P-deficient conditions.

297 2.5.2. Set up of the experiment

298 Preliminary experiments with different soil/solution ratios and different shaking times 299 allowed for the definition of adequate conditions to reach an apparent steady state between 300 soil and solution. A $50 \mathrm{~mL}$ vial was filled with $4 \mathrm{~g}$ of dry soil sieved at $2 \mathrm{~mm}$ and $20 \mathrm{~mL}$ of 301 solution to reach the solution/soil ratio of $5 \mathrm{~V} / \mathrm{m}$ (OECD, 2000). Six conditions were tested in 302 triplicates: $\mathrm{P}+$ and $\mathrm{P}-$ nutrient solutions previously described, $0\left(\mathrm{C}_{0}\right), 10.15\left(\mathrm{C}_{10}\right)$ and 40.6 $303\left(\mathrm{C}_{40}\right) \mathrm{mg} \mathrm{L}^{-1}$ citric acid.

304 Two kinds of batches were tested: in the "continuous batch" the same solution was kept in $\mathrm{n}$ 305 contacts with the soil for 5 days; in the "serial batch" the solution was renewed every $24 \mathrm{~h}$ to 306 mimic the rhizotest experiments, the change of solution being considered as a surrogate of the 307 "root uptake" effect. Batches were agitated at $400 \mathrm{rpm}$ in a controlled incubator (dark, $\left.30825 \pm 1^{\circ} \mathrm{C}\right)$. After $24 \mathrm{~h}$ or $120 \mathrm{~h}$, vials were centrifuged $(6500 \mathrm{~g}, 1 \mathrm{~h}$ - Centrifuge 5430R, 309 Eppendorf and Biofuge Stratos, Heraeus Instruments). The supernatants were recovered, 310 filtered at $0.45 \mu \mathrm{m}$ (polyethersulfone, VWR) and kept at $4{ }^{\circ} \mathrm{C}$ until analysis. Uranium and 311 major cations ( $\mathrm{K}, \mathrm{Ca}, \mathrm{Mg}, \mathrm{Na}, \mathrm{Fe}$ ) contents of the supernatants were analysed by ICP-AES 312 and anions including organic acids and phosphate by ILC, as described above. Organic and 
313 inorganic anions were analysed in one of the 3 replicates for each condition (P/citrate/type of

314 batch/step). Calculations were performed taking into account the remaining solution in the

315 soil residue after each centrifugation step.

316 Soil 2 was subjected to the same protocol than soil 1 (supplementary material S4).

318 2.5.3. Theoretical considerations and calculations

319 In batch systems, cations (among which U), inorganic anions (among which P), and organic 320 acids (among which citrate) dynamically interacted with the soil, whether they were 321 introduced with the test solution and/or extracted from the soil. They could be either released 322 (desorbed) from the solid phase or disappear from the solution (being either sorbed, or part of 323 a precipitation process or degraded). Both processes can occur simultaneously and the 324 resulting measured concentration in solution indicated the dominant process.

325 Calculations were done according to Teramage et al. (2017) and are detailed below for U. The 326 underlying hypothesis is that a fraction of $U$ in soil is available (named $U_{\text {avail }}$ ) and thus 327 equilibrates with the solution, with a partition coefficient named $\mathrm{k}_{\mathrm{d}_{-} \mathrm{U}}$, and that a fraction $328\left(\% \mathrm{U}_{\text {fixed }}\right)$ remains fixed on the soil solid phase and never participates in the equilibrium 329 process. At each step of the batch experiment, the mass balance of $U$ in the batch is conserved. 330 The analysis of $U$ only in the supernatants at the end of each step, allows, based on mass 331 balance, to calculate the resulting $U$ concentration in the solid phase. The concentration of $U$ 332 on the soil solid phase is expressed by the following equations:

$333 C_{U_{-} \text {solid_total_initial }}=C_{U_{-} \text {solid_available_initial }}+C_{U_{-} \text {solid_fixed_initial }}$

$334 C_{U_{-} \text {solid_total_final }}=C_{U_{-} \text {solid_available_final }}+C_{U_{-} \text {solid_fixed_final }_{-}}$

335 with $C_{U_{-} \text {solid_total_initial }}, C_{U_{-} \text {solid_total_final }}, C_{U_{-} \text {solid_available_initial }}$ and $C_{U_{-} \text {solid_available_final }}$

336 respectively the total and available $U$ concentrations $\left(\mathrm{mg} \mathrm{g}^{-1}\right)$ at the initial and final step. The 
337 initial concentration of fixed element is supposed to be constant throughout the experiment as

338 the hypothesis is that it does not participate in the equilibrium process.

339 The equilibrium between $C_{U_{-} \text {solid-available_final }}$ and $C_{U_{-} \text {solid-total-final }}$ is given by the following 340 equation:

$341 C_{U_{-} \text {solid_available_final }}=k_{d_{-} U}^{\prime} \times C_{U_{-} \text {solution }_{-} \text {final }}$

342 where $C_{U_{-} \text {solution_final }}$ is the $\mathrm{U}$ concentration (in $\mathrm{mg} \mathrm{L}^{-1}$ ) in the solution at the end of the batch

343 step considered and $k_{d_{-} U}^{\prime}\left(\mathrm{L} . \mathrm{kg}^{-1}\right)$ is the partition coefficient between the solid available

344 fraction and the solution.

345 Merging equations (Eq2) and (Eq3) gives the following formula, which is verified at each 346 step of the batch experiment:

$347 C_{U_{-} \text {solid_total_final }}=k_{d_{-} U}^{\prime} \times C_{U_{-} \text {solution_final }}+C_{U_{-} \text {solid_fixed_initial }}$

348 Finally, $C_{U_{-} \text {solid_total_final }}$ is plotted against $C_{U_{-} \text {solution_final }}$ for each step, which allows deducing

$349 k_{d_{-} U}^{\prime}$ which is the slope of the linear part of the curve and $C_{U_{-} \text {solid_fixed_initial }}$ the y-intercept. 350 The $\%$ of $U$ as available and fixed pools can then be calculated.

351 The dataset was not complete for the $\mathrm{C}_{10}$ condition on soil 2 . Thus, for soil 2 only results for $352 \quad \mathrm{C}_{0}$ and $\mathrm{C}_{40}$ will be displayed.

353

354 2.7. Statistical analysis

355 All statistical analyses were performed with R software (R Development Core Team, 2011).

356 Results were subjected to one-way and two-way analysis of variance (ANOVA) with Tukey 357 posthoc tests. Normality of the distributions and homogeneity of variance were verified by the 358 appropriate tests and graphically on residuals. Heteroscedasticity was corrected when necessary by variance modelling. Results of posthoc tests are displayed through use of 
360 different letters. Displayed values are generally means of 5 rhizotests or 3 batches, with their 361 corresponding standard error ( \pm s.e. $)$.

363 3. Results

364 This chapter display results obtained with soil 1. Equivalent results obtained with soil 2,

365 which can thus be viewed as a kind of replicate study, may be seen in supplementary material 366 S4.

368 3.1. Relationship between root exudation and U transfers to plants (Rhizotests)

369 3.1.1 U accumulation in lupine plants

370 Most of the $\mathrm{U}$ was recovered in the roots (Fig. 3a) and root-to-shoot translocation was low 371 (Fig. 3b, 3d). Accumulation in roots (Fig 3a.) was slightly higher in P-condition (19.6 mg U $372 \mathrm{~kg}^{-1}$ d.w. roots $)$ than in $\mathrm{P}+$ condition $\left(17.8 \mathrm{mg} \mathrm{U} \mathrm{kg}^{-1}\right.$ d.w. roots $)$. Uranium accumulation in shoots 373 (Fig. 3b) and shoot to root ratio (Fig. 3d) was higher in $\mathrm{P}+$ condition than in $\mathrm{P}-$ condition. Yet,

374 shoot $\mathrm{U}$ content was 4 times higher in $\mathrm{P}+$ condition than in $\mathrm{P}$ - condition, but, due to the higher 375 prevalence of root $\mathrm{U}$ stock, at the whole plant level, $\mathrm{U}$ content was equivalent in both $\mathrm{P}$ 376 condition.

378 3.1.2. Root exudation of organic acids

379 Exudation was measured for each rhizotest at the end of the pre-culture and after exposure to 380 soil. The results are displayed on Figure 4a for citrate, Figure $4 \mathrm{~b}$ for oxalate and Figure 4c for 381 formate.

382 Exudation was variable from one rhizotest to another and the different organic acids had 383 different patterns. Exposure to soil 1 as compared to the pre-culture results increased citrate 384 exudation in both $\mathrm{P}$ conditions. The level of citrate exudation was especially high in $\mathrm{P}+$ 
condition $\left(193 \mu\right.$ mol $_{\text {citrate }} \mathrm{kg}^{-1}$ d.w. roots $\left.\mathrm{h}^{-1}\right)$ and it was higher than in the $\mathrm{P}-$ condition (93

$386 \mu \mathrm{mol}_{\text {citrate }} \mathrm{kg}^{-1}$ d.w.roots $\mathrm{h}^{-1}$ ), although the ANOVA did not find the results significantly different

387 due to high standard errors. In addition, citrate exudation was higher after soil exposure than

388 in the corresponding controls which were exposed 5 days to nutrient solution.

389 Exposure to soil 1 increased oxalate exudation in the same way as that recorded for citrate for

390 both conditions, except that oxalate flux (around $150 \mu \mathrm{mol}_{\text {oxalate }} \mathrm{kg}^{-1}{ }_{\text {d.w. roots }} \mathrm{h}^{-1}$ ) was higher

391 than citrate flux. In addition, the level of oxalate exudation recorded on controls, after

392 exposure was also higher than at the end of pre-culture. Exposure to soil 1 increased only

393 slightly formate exudation. Surprisingly, the level of formate exudation recorded on controls

394 was higher than those recorded with soil 1 . The other organic acids were either absent or 395 under the detection limit (acetate, lactate) or not quantifiable by our current analytical 396 protocol.

397

398 3.1.3. Role of organic acids in the $\mathrm{U}$ transfer to plants

399 In order to assess the potential role of organic acids, especially citrate, in the U transfer to 400 plants, $\mathrm{U}$ accumulation in shoots $\left(\mathrm{U}_{\text {transloc }}\right.$ ) and total $\mathrm{U}$ uptake (total $\mathrm{U}$ in plant as related to dry 401 matter of roots, $\mathrm{U}_{\text {up }}$ ) is displayed in figure 5, as related to the variation in citrate exudation 402 rate measured between beginning and end of exposure period.

403 The $\mathrm{U}$ measurements in plants illustrate that less than $0.3 \%$ of $\mathrm{U}$ absorbed by plant was 404 translocated to shoots whatever the conditions. At the whole plant level (Fig 5a.) the U 405 transfer did not correlate either with the P nutrition or the level of citrate exudation as similar 406 values of $\mathrm{U}$ are recorded at different mean exudation rates. On the contrary, translocation in 407 shoots seems to correlate with the corresponding level of citrate exudation for each soil 408 (difference between P- and P+). 
3.2. $U$ behaviour in soils in the presence of citrate (Batch experiments)

411 The batch experiment aimed at assessing the behaviour of $U$ in the U-contaminated soil exposed to a known citrate concentration, with no other organic acids added (as compared to 413 exudates) and no interference of plant physiology. Results obtained for $U$ are displayed on 414 Figure 6.

415 Results are equivalent in $\mathrm{P}-$ and $\mathrm{P}+$ conditions. The total amount of $\mathrm{U}$ desorbed is higher in 416 serial (2-5 times) than in continuous batch, due mainly to the high extraction rate recorded 417 during the first step. The addition of citrate increases the \% U desorbed at first step. During 418 the second step there was an inverse relation between \% $\mathrm{U}$ desorbed and citrate concentration 419 and no effect of citrate during the last 3 steps although citrate was still added in the solution. 420 No citrate effect on total U desorbed was recorded in the continuous batch.

421 The final $U$ concentrations on the solid phase and $U$ concentrations in solution at each batch 422 step were plotted, as illustrated on Figure 7. Results of the serial batches were fitted with a 423 linear regression model, considering only the steps 2 to 5, as results obtained for the first step 424 showed systematically a very different behaviour from the other steps, an indication either of 425 transitory equilibrium and/or effect of peculiar mechanisms. The linear regression allows, as 426 detailed in the calculation section, generating the slopes and y-intercepts for Eq. 4, the latter 427 corresponding to the \% U fixed (non-available) that further gives the \% "available" U (Figure 428 8a). This pool is further qualified as "extractable pool" as it may be confusing to call it 429 "available" pool when citrate concentrations are applied to the soil. Results obtained in P+ 430 and P-conditions were not significantly different. With increasing citrate concentration, the 431 value for $1^{\text {st }}$ step of the serial batch diverged towards higher $U$ concentration in solution, 432 which illustrated that mechanisms during the $1^{\text {st }}$ day were different from the other steps. The 433 relative difference in the results for the further steps is related to the extent of U release during 434 the first step, but, as revealed by the close slopes of the regression lines, the behaviour of $U$ 
435 then is independent of $\mathrm{P}$ and citrate. For the $\mathrm{C} 0$ condition, the value of continuous batch was

436 in good agreement with the linear function defined within steps 2 to 5. With increasing citrate,

437 values diverged on the left-hand side of the equilibrium line.

438 In the absence of citrate, the $U$ extractable pool was estimated to be $0.4 \pm 0.1 \%$ of total soil $U$

439 (Fig 8a.). The size of the extractable pool was not changed with the low citrate concentration

440 (C10), but increased up to $0.75 \%$ with the high citrate concentration (C40), up to $0.75 \%$. The

441 extractable pool was easily accessible as shown by the corresponding low $\mathrm{k}_{\mathrm{d}}$ ' values for all modalities (Fig 8b). Values are different from those of "soluble U" displayed in Table 1 as

443 they were not acquired in the same medium (nutrient solution vs water) and time.

444

445 3.3. Fe, $\mathrm{Ca}, \mathrm{P}$ and organic acids behavior in batch experiment

446 Cations, anions and organic acids were analysed in one replicate of each group of 3 batches, 447 chosen randomly. Results obtained for $\mathrm{Ca}, \mathrm{Fe}$, citrate and oxalate are displayed respectively 448 on Figure 9a, 9b, 9c and 9d. Phosphate concentration was undetectable in solution whatever 449 the step and condition indicating that phosphate was immediately sorbed and both initial 450 conditions (P- and $\mathrm{P}+$ ) ended up with the same soil solution composition. Except for the first 451 day in serial batches (in which $20 \%$ of initial citrate was recovered in $\mathrm{P}-$ and $34 \%$ in $\mathrm{P}+$, 452 whatever the citrate concentration), citrate was nearly totally consumed during all steps (Fig. 453 9c). Calcium, and Fe concentrations in the batch solutions decreased during most steps and a 454 correlation between $\mathrm{Fe}$ and $\mathrm{U}$ behaviours was found in initial steps in particular (as revealed 455 by Kendall and Spearman correlation coefficient of 0.95 ). For continuous batch, around $12 \%$ $456 \mathrm{Fe}$ (in $\mathrm{P}-$ and $\mathrm{P}+$ ) initially present in solution disappeared, with no real difference between 457 citrate conditions (Fig. 9b). Removal of Ca from solution was higher (35.7\%) in P- condition 458 than in $\mathrm{P}+$ condition (13.1\%) in the absence of citrate (Fig. 9a). With increasing citrate, the \% 459 of Ca removed from solution increased to $30 \%$ in P+. For serial batch steps 2 to 5, around 
$46030 \%$ of $\mathrm{Fe}$ and $35-40 \%$ of $\mathrm{Ca}$ disappeared, with no clear difference between $\mathrm{P}$ and citrate 461 conditions (with the exception of C40_P+_day 4 condition which value was $60 \%$ ). During 462 the first step of the serial batch, there was a marked decrease in Fe concentration in the P+ 463 condition (40\%) compared to P- condition (13.1\%). Increasing the citrate concentration 464 resulted for the highest citrate concentration in a release of $\mathrm{Fe}$, the latter being higher in $\mathrm{P}+$ 465 than in $\mathrm{P}$ - condition. On the second day, removal of Fe in $\mathrm{P}+$ condition $(22-25 \%)$ reached a 466 value that was still recorded at ulterior steps. In P- condition, Fe was less consumed in $\mathrm{C} 0$ and 467 C10 conditions, with a release in C40 condition. Ca was consumed at each step with values 468 of \% Ca removed between 15 and $30 \%$ at day 1 and $35-40 \%$ further on. A small quantity of 469 oxalate (5-10 $\mathrm{mg} \mathrm{kg}^{-1}$ dry soil) was released especially during the first day in serial batches, with 470 lower values afterwards and in the continuous batches (Fig. 9d).

471

472 4. Discussion

473 Citrate addition in soils as an amendment is known to increase U solubility in the soil solution 474 and further U transfer to plants (Huang et al., 1998; Mihalik et al., 2012). Roots of P-deficient 475 plants are known to exudate large levels of organic acids, among which citrate, in order to 476 increase $\mathrm{P}$ availability. Many soils may have low available $\mathrm{P}$ contents whether their total $\mathrm{P}$ 477 content is high or not. There is thus an interest in unravelling mechanisms involving root 478 exudation of citrate, $\mathrm{P}$ acquisition, $\mathrm{U}$ release and ultimately plant uptake in the rhizosphere in 479 particular of plants combining exudation of protons and chelators for $\mathrm{P}$ or $\mathrm{Fe}$ (so called 480 "strategy I plants") acquisition.

481 To answer the question (whether citrate exudation may modulate $U$ release and uptake), we 482 used a modified version of the RHIZOtest ${ }^{\circledR}$, which is a normalized biotest, two naturally Ucontaminated soils (in which $\mathrm{U}$ is supposed to be at equilibrium with the solid phase) and lupine as model plant, which exudation was piloted by P-nutrition level. The rhizotest 
experiment was combined with batch experiments, providing some insights into the dynamics

486 of elements between soil and solution (principally $U$ ), and quantifying the $U$ available pool.

487 As exposed ion the 'soil' issue of the "Material and Methods' chapter, a second soil (soil 2) of

488 similar properties but a higher $\mathrm{U}$ content (500 mg $\mathrm{U} \mathrm{kg}^{-1}$ soil) and possible different behavior 489 regarding speciation, migration or (bio) availability of $U$ was tested. Results were equivalent 490 and thus validate all statements made in this document for soil 1.

491

$492 \quad$ U and other elements dynamics in the soils (batch experiments)

493 The batch experiment aimed at giving insights on $U$ behaviour in the tested soil in the 494 presence of two P levels and two levels of citrate taken as model of exudate, considered as 495 representative of those that could occur in the rhizotest experiment. Apart from U, which 496 results have been detailed in the results section (Fig. 6, Fig. 7, Fig. 8), the dynamics of other 497 major cations, anions and organic acids was recorded, with a specific focus on those that 498 could form soluble complexes with citrate (U, Fe, P) and/or degrade (citrate) and/or be 499 involved in sorption/precipitation processes with/without $\mathrm{U}\left(\mathrm{Ca}, \mathrm{PO}_{4}\right.$, citrate) (Fig. 9).

500 Phosphate concentration was undetectable in solution whatever the step and condition 501 indicating that phosphate was immediately sorbed and both initial conditions ( $\mathrm{P}-$ and $\mathrm{P}+$ ) 502 ended up with the same soil solution composition. As a result, the main differences were 503 observed between the different citrate concentrations only. Except for the first day citrate was 504 nearly totally consumed during all steps, and calcium or Fe concentrations in the batch 505 solutions decreased during most steps. Contrary to citrate, oxalate was not introduced in the 506 system. The batch experiment was not conducted in sterile conditions, thus organic acids may 507 be produced by microbial activity. No other organic acid was released, including citrate in C0 508 condition. 
These results gave some insights into complex interactions and exchanges between elements

510 in the batches. Phosphate and citrate removed from solution, together with $\mathrm{Ca}$ suggest

511 complex associations between these ions and the soil matrix. Fe releases at high citrate

512 concentration, and its correlation with $\mathrm{U}$, suggest that citrate had an effect on a common

513 bearing phase. This result suggests that at least part of the "available pool" of U could be

514 related to a Fe-bearing phase, also susceptible to desorption in the presence of citrate. Yet,

515 previous studies on these soils had suggested that $U$ may be associated with Fe516 oxi(hydr)oxides (Pfeifer et al., 1994). The importance of adsorption of $U$ on Fe517 oxi(hydr)oxides and its consequences on $U$ dynamics in soils are well known (Hsi and 518 Langmuir, 1985; Waite et al., 1994; Duff and Amrhein, 1996; Payne et al., 1996; Lenhart and 519 Honeyman, 1999). At the soil $\mathrm{pH}$ (5.26 for soil 1), these oxides are positively charged thus 520 citrate, oxalate and phosphate ions can interact with them (Hsu, 1964; Parfitt et al., 1975; 521 Goldberg and Sposito, 1984). This is coherent with the observed decrease in citrate 522 concentration over time in the solution during our experiments. In addition, studies by 523 Oburger et al. (2011a,b) have shown that equilibrium between citrate or phosphate and soil 524 may be rapid, especially on Fe-bearing phases.

525 Because the batches were not performed in sterile conditions, degradation of citrate and 526 oxalate by microorganisms, which is known to be rapid (half-life of only a few hours; Jones, 527 1998), may have occurred in the continuous batch, resulting in the destruction of the 528 complexes initially formed between citrate and U (Figure 6) and thus in the release of U (and $529 \mathrm{Fe}, \mathrm{P})$ which in turn could have undergone precipitation or re-adsorption processes on the 530 solid phase (Hafsteinsdóttir et al., 2015). Citrate, positively charged Fe oxides and U may also 531 be involved in the formation of ternary complexes, leading to the same result (Fein, 2002). 532 Allard et al. (1999) have studied the products of U-weathering form U deposits in the Massif 533 Central (France). They have shown that oxidation of $U$ may lead to the formation of 
534 associations with $\mathrm{Si}$ and $\mathrm{Al}$ that could then be entrapped in hydrous ferric oxides during ion

535 precipitation. As U originates from a pitchblende vein, the studied soil sampled downwards

536 the vein may have accumulated $U$ either through particulate transport/erosion or in dissolved

537 form and subsequent immobilisation through secondary $U$ associations. Thus some of the

538 processes mentioned above may have already occurred in this soil prior to its use in the batch

539 experiment. Additional results of DRX and $\mu$-fluorescence analyses performed on some soil

540 samples (supplementary material S3) are in agreement with those statements as they have

541 shown a mix of homogeneous $U$ contamination and hotspots, and possible $U$ secondary

542 associations as stated in Allard et al. (1999) that could result in different U "bearing-phases",

543 characterized by different reactivity with citrate leading to variable U lability in the soil.

544 In absence of citrate, the continuous batch results are in accordance with the equilibrium

545 model fitted on steps $2-5$ of the serial batch. With increasing citrate concentration, the ratio

546 between $U$ in solid and liquid phases moved away from the line defining equilibrium. Such

547 disequilibrium is generally due to kinetic limitations, possibly involving rearrangements of $U$

548 interactions during the process.

549 During the first step of the serial batch, there was a high release of U, independent of P level

550 but correlated to citrate concentration. As the soil was introduced dry in the batches, we

551 hypothesized that soil manipulation and imbibition at the moment of batch launching had

552 triggered a "priming effect" that could have either released dissolved organic carbon in

553 solution and/or boosted microorganisms that can either exudate organic acids (Jenkinson,

554 1966; Eschenbach et al., 1998) or degrade them (Jones, 1998). This peak of chelates release

555 (see for example the oxalate release, Fig. 9d) was responsible for the high U desorption in the

556 absence of citrate and was superimposed to the citrate effect for the 2 other conditions. This

557 phenomenon has also certainly occurred in the continuous batch, but degradation of citrate or 
558 oxalate may have participated to their further disappearance in solution, in addition to their

559 sorption onto the solid phase or precipitation/sorption of elements including $\mathrm{U}$.

561 U phytoavailability and influence of exudation (Rhizotest experiment)

\section{$562 \quad$ U uptake and translocation}

563 The mean $U$ concentration ratio (CR, ratio of shoot $U$ concentration to soil $U$ concentration at

564 the end of exposure) of lupine plants after 5-days exposure to soils in the rhizotest was

$565(1.1 \pm 0.1) 10^{-3}$. Despite a limited time of exposure, the experimental CR was in accordance

566 with Transfer Factor (analog of CR) values reported in the literature (IAEA, 2010) for

567 leguminous fodder and the closest soil category tabulated, i.e. "sand" (mean value $2.410^{-3}$,

568 GSD 3.7). In accordance with existing data (Dushenkov et al., 1997; Shahandeh and Hossner,

569 2002; Laroche, 2005; Misson et al., 2009; Straczek et al., 2010), most of the U was recovered

570 in the roots and root-to-shoot translocation was low $(<0.3 \%$ of total plant U). Uranium

571 accumulation at the whole plant level is thus equivalent in both $\mathrm{P}$ conditions due to the

572 prevalence of root concentration (Fig 3a. and Fig 3c.). Uranium content of shoots was higher

573 in P+ than in P- condition for both soils (Fig 3b. and Fig 3d.).

574 The differences between $\mathrm{P}$ conditions were not related to differences in the water flux through

575 the rhizotest, as they were equivalent in all experiments (Supplementary material S2).

\section{Effects of citrate exudation on phytoavailability}

578 According to our calculations, batch results in $\mathrm{C} 0$ condition were used to estimate the $\mathrm{U}$

579 available pool in the rhizotest experiment. Plotting $U$ accumulation results as a function of

580 citrate exudation has shown that $\mathrm{U}$ translocated to shoots (Fig $5 \mathrm{~b}$ ), but not $\mathrm{U}$ accumulated in 581 the whole plants (Fig 5a), was correlated to citrate exudation. The level of citrate exudation of 582 lupine on soil, either for $\mathrm{P}+$ or $\mathrm{P}$ - conditions, may be related respectively to $\mathrm{C} 40$ and $\mathrm{C} 10$ 
583 citrate conditions used in the batch experiment. The batch results have shown that the size of

584 extractable U pool (Fig. 8a) increased at the highest citrate concentration. The associated $\mathrm{k}_{\mathrm{d}}$ '

585 values (Fig. 8b) were low whatever the conditions and even decreased with increasing citrate,

586 which showed that the extractable pool was easily desorbed. Levels of $U$ desorbed in

587 continuous batch were also equivalent whatever $\mathrm{P}$ and citrate condition.

588 From our results, we may conclude that: i) a small but easily accessible available U pool

589 exists in soil (even in the absence of complexing agents), and therefore ii) exudation of 590 organic acids such as citrate do not affect significantly U availability. Our results shows also

591 that $U$ accumulated by lupine represented less than $50 \%$ of the $U$ available pool: $U$ 592 accumulated by lupine plants corresponded to $27.8 \pm 4.1 \%$ and $25.8 \pm 2.7 \%$ of the $U$ available 593 pool respectively for the $\mathrm{P}$ - and $\mathrm{P}+$ conditions. Buffering of the soil solution by the solid 594 phase was supposed to be the limiting step for phytoavailability and not plant uptake. Indeed, 595 the affinity of plant roots for U, even if not further translocated, is high (Dushenkov et al., 596 1997; Shahandeh and Hossner, 2002; Laroche, 2005; Misson et al., 2009; Straczek et al., 597 2010). Moreover, in our experimental conditions, a combination of factors may have limited 598 the diffusion of $U$ to roots and favoured the soil solution/root step limitation: e.g. the low 599 duration of contact and the geometry of rhizotest (only the surface of roots in contact with 600 basal membrane is efficient for uptake). However, it should be kept in mind that the 601 phytoavailability, as measured in our rhizotest experiment conditions, is thus only 602 representative of a short time window compared to the whole growth cycle of the plant.

603 Part of the U absorbed by roots may be translocated to shoots, through internal physiological 604 mechanisms that are not fully dependant of the processes controlling $U$ exchanges at the 605 solution/root interface. In the rhizotest experiment, a differential translocation of $U$ to shoots 606 of lupine plants with P status was recorded, that may be linked to the citrate exudation level. 607 It has been shown that citrate enhanced U translocation to shoots (Laurette et al., 2012a,b; 
608 Mihalik et al., 2012), with two underlying possible processes: uptake of citrate-U complexes

609 or buffering of the soil solution with uranyl ion through complex dissociation at the root 610 interface. Both may explain the enhanced translocation recorded for soil in $\mathrm{P}+$ condition, as it

611 is affected by higher citrate exudation rate in that condition.

612

613 Effects of exudation of organic acids on soils

614 Citrate was not the only organic acid exuded by lupine roots. For example, oxalate was also 615 exuded at a higher rate than citrate (Figure 4), as also already recorded for lupine by Mimmo 616 et al. (2011). Generally, citrate and malate are the two most studied organic acids regarding 617 lupine exudation, and citrate seems to be the most effective organic acid in solubilizing 618 inorganic phosphorus (Pi) (Oburger et al., 2011a). Oburger et al. (2011a, b) have intensively 619 studied the dynamics of $\mathrm{Pi}$ and citrate in soils in order to extrapolate to rhizospheric 620 conditions. They concluded on a complex mechanism, not fully understood and depending on 621 numerous parameters such as soil $\mathrm{pH}$, quantity of $\mathrm{Fe} / \mathrm{Al}$ oxy/hydroxides (as binding phase for 622 Pi and citrate) and concentration of metals (e.g; Fe) or other competing cations $(\mathrm{Ca})$ in the soil 623 solution, and the respective effect of organic acids as chelates and the concomitant release of 624 protons. All of these parameters have been shown to interfere with $U$ behaviour as also 625 observed in our soil/plant system. Yet, in many studies including that of Mimmo et al. (2011), 626 the effect of organic acids other than citrate, as well as mix of organic acids, or more 627 generally rhizosphere exudation, on soil dynamics is not always described while they may be 628 produced in significant amounts, as shown in our experiments (Fig. 4). It may be cumulative, 629 and a better assessment of total exudation could be a more effective determinant of $U$ 630 availability/phytoavailability than solely citrate exudation. 
633 This study aimed at testing if root exudation of a model organic acid, citrate, could influence

$634 \mathrm{U}$ availability and phytoavailability for lupine plants. The hypothesis was that citrate would 635 enhance U phytoavailability, through the same mechanisms as those shown by citrate-assisted 636 phytoextraction studies. High exudation of citrate is known to occur in P-deficient plants, thus 637 the level of $\mathrm{P}$ was used to modulate plant physiology and exudation level, which has 638 introduced more complexity in the system. Batch experiment was conducted to assess the 639 influence of citrate alone on $U$ availability at the soil/solution interface. The results show that 640 the U-available pool was of limited size, but was easily extractable. As a consequence, in only 641 one-week-exposure of the soil to lupine plants (exudation and uptake), up to $25-40 \%$ of the U-

642 available pool depending the conditions was removed. Due to the complexity of the system, 643 and also potentially to the apparent insensitivity of $U$ available pool to citrate, it was not 644 possible to conclude on the effect of citrate exudation on the U phytoavailability in the tested 645 conditions. However, we showed that $U$ translocation was a function of the citrate exudation 646 level. Thus, the question of whether exudates may participate in the phytoavailability of $U$ is 647 still as stake, for example in soils where U speciation may be more significantly affected by 648 the effect of organic acids. In addition, the combined effects of plant strategies towards 649 acquisition of both $\mathrm{Fe}$ and $\mathrm{P}$ (through $\mathrm{pH}$ modification and/or exudation of protons/organic 650 acids/phytosiderophores) on U phytoavailability should be assessed in future studies, at the 651 root interface as well as for the whole growth cycle of plants.

653 Acknowledgments: Authors are very grateful to all reviewers for their valuable suggested 654 improvements of the manuscript and to Daniel Borschneck (CEREGE) for the help in the X655 ray fluorescence analysis. 
658 Aery, N.C., Jain, G.S., 1997. Effect of uranyl nitrate on seed germination and early seedling 659 growth on Triticum aestivum. Biologia (Bratislava). 52(1), 115-119.

660 Allard, T., Ildefonse, P., Beaucaire, C., Calas, G., 1999. Structural chemistry of uranium

661 associated with Si, Al, Fe gels in a granitic uranium mine. Chemical Geol. 158, 81-103.

662 Bourrelier, P.-H., Berthelin, J., 1998. Contamination des sols par les éléments en traces : les 663 risques et leur gestion. TEC \& DOC Lavoisier, Paris, France.

664 Bravin, M.N., Michaud, A.M., Larabi, B., Hinsinger, P., 2010. RHIZOtest: a plant-based 665 biotest to account for rhizosphere processes when assessing copper bioavailability. Environ. 666 Pollut. 158, 3330-3337.

667 Briat, J.F., 2008. Iron dynamics in plants. Adv. Bot. Res. 46, 137-180.

668 Chaignon, V., Hinsinger, P., 2003. A biotest for evaluating copper bioavailability to plants in 669 a contaminated soil. J. Environ. Qual. 32, 824-833.

670 Doustaly, F., Combes, F., Fiévet J.B., Berthet, S., Hugouvieux, V., Bastien, O., Aranjuelo, I., 671 Leonhardt, N., Rivasseau, C., Carrière, M., Vavasseur, A., Renou, J.-P., Vandenbrouck, Y., 672 Bourguignon, J., 2014. Uranium perturbs signalling and iron uptake response in Arabidopsis 673 thaliana roots. Metallomics. 6, 809-821.

674 Duff, M.C., Amrhein, C., 1996. U(VI) sorption on goethite and soil in carbonate solutions. 675 Soil Sci. Soc. Am. J. 60, 1393-1400.

676 Duffner, A., Hoffland, E., Temminghoff, E.J.M., 2012. Bioavailability of zinc and 677 phosphorus in calcareous soils as affected by citrate exudation. Plant Soil, 361(1-2), 165$678 \quad 175$.

679 Duquène, L., Tack, F., Meers, E., Baeten, J., Wanninjn, H., Vandenhove, H., 2008. Effect of 680 biodegradable amendments on uranium solubility in contaminated soils. Sci. Tot. Environ. $681391,26-33$. 
682 Dushenkov, S., Vasudev, D., Kapulnik, Y., Gleba, D., Fleisher, D., Ting, K.C., Ensley, B., 683 1997. Removal of uranium from water using terrestrial plants. Environ. Sci. Technol. 31, $684 \quad 3468-3474$.

685 Ebbs, S.D., Brady, D.J., Kochian, L.V., 1998. Role of uranium speciation in the uptake and 686 translocation of uranium by plants. J. Exp. Bot. 49(324), 1183-1190.

687 Eschenbach, A., Wienberg, R., Mahro, B., 1998. Fate and stability of non-extractable residues 688 of ${ }^{14} \mathrm{C}$ PAH in contaminated soils under environmental stress conditions. Environ. Sci. 689 Technol. 32, 2585-2590.

690 Fein, J.B., 2002. The effects of ternary surface complexes on the adsorption of metal cations 691 and organic acids onto mineral surfaces. Water-Rock Interactions, Ore Deposits and 692 Environmental Geochemistry: A tribute to David A. Crerar. The Geochemical Society, 693 Special Publication n ${ }^{\circ}$, Hellmann R. and Wood S.A. Eds.

694 Fuller, C.C., Bargar, J.R., Davis J.A., Piana, M.J., 2002. Mechanisms of uranium interactions 695 with hydroxyapatite: implications for groundwater remediation. Environ. Sci. Technol. 36, $696 \quad 158-165$.

697 Goldberg, S., Sposito, G., 1984. A chemical model of phosphate adsorption by soils: I. 698 reference oxide minerals. Soil Sci. Soc. Am. J. 48(4), 772-778.

699 Hafsteinsdóttir, E.G., Camenzulli, D., Rocavert, A.L., Walworth, J., Gore, D.B., 2015.

700 Chemical immobilization of metals and metalloids by phosphates. Appl. Geochem. 59, 47701 62.

702 Hinsinger, P., 1998. How do plant roots acquire mineral nutrients? Adv. Agron. 64, 225-265. 703 Hinsinger, P., 2001. Bioavailability of soil inorganic P in the rhizosphere as affected by root704 induced chemical changes: a review. Plant Soil 237, 173-195.

705 Hinsinger, P.,Gobran, G., Wenzel, W.W., 2005. Rhizosphere geometry and heterogeneity 706 arising from root-mediated physical and chemical processes. New Phytol. 168, 293-303. 
707 Horst; W., 2011. Composition of solution for exudate collection. Personal communication.

708 Hsi, C.K.D., Langmuir, D., 1985. Adsorption of uranyl onto ferric oxyhydroxides: application

709 of the surface complexation site-binding model. Geochim. Cosmochim. Acta. 49, 1931-

7101941.

711 Hsu, P.H., 1964. Adsorption of phosphate by aluminium and iron in soils. Soil Sci. Soc. Am.

$712 \quad$ J., 28(4), 474-478.

713 Huang, J.W., Blaylock, M.J., Kapulnik, Y., Ensley, B.D., 1998. Phytoremediation of

714 uranium-contaminated soils: Role of organic acids in triggering uranium hyperaccumulation

715 in plants. Environ. Sci. Technol. 32, 2004-2008.

716 IAEA-International Atomic Energy Agency, 2010. Handbook of parameter values for the

717 prediction of radionuclide transfer in terrestrial and freshwater environments. Technical

718 Reports Series n472, 208p.

719 Jenkinson, D.S., 1966. The priming action. In "The use of isotope in soil organic matter

720 studies”, Braunschweig, Pergamon Press, New York (United States), p 199-208. Report for

721 the FAO/IAEA.

722 Jones, S.L., 1998. Organic acids in the rhizosphere- a critical review. Plant Soil. 205, 25-44.

723 Kahm, M., Horst, W.J., Amer, F., Mostafa, H., Maier, P., 1999. Mobilization of soil and

724 fertilizer phosphate by cover crops. Plant Soil 211, 19-27.

725 Keerthisinghe, G., Hocking, P.J., Ryan, P.R., Delhaize, E., 1998. Effect of phosphorus supply

726 on the formation and function of proteoïd roots of white lupin (Lupinus albus L.). Plant Cell

727 Environ. 21(5), 103-122.

728 Laroche, L., 2005. Transfert racinaire de l'uranium (VI) en solution chez une plante

729 supérieure : spéciation en solution hydroponique, prise en charge par la plante,

730 microlocalisation et effets biologiques induits. Thèse doctorat en Sciences de 
731 l'Environnement, spécialité Biosciences de l'environnement, chimie et santé, Université 732 d'Aix-Marseille 1, nº ISRN IRSN-2005/52-FR, 242p.

733 Laurette, J., Larue, C., Llorens, I., Jaillard, D., Jouneau, P.-H., Bourguignon, J., Carrière, M.,

734 2012a. Speciation of uranium in plants upon root accumulation and root-to-shoot

735 translocation: a XAS and TEM study. Env. Exp. Bot. 77, 87-95.

736 Laurette, J., Larue, C., Mariet, C., Brisset, F., Khodja, H., P.-H., Bourguignon, J., Carrière, M., 737 2012b. Influence of uranium speciation on its accumulation and translocation in three plant 738 species: oilseed rape, sunflower and wheat. Env. Exp. Bot., 77, 96-107.

739 Lenhart, J.J., Honeyman, B.D., 1999. Uranium(VI) sorption to hematite in the presence of 740 humic acid. Geochim. Cosmochim. Acta 63, 2891-2901.

741 McLaughlin, M.J., Smolders, E., Merckx, E., 1998. Soil-root interface: Physico-chemical 742 processes. In Huang, P.M., Adriano, D.C., Logan, T.J., Checkai, R.YT. (Eds) Soil chemistry 743 and ecosystem health. Special Publication ${ }^{\circ}{ }^{\circ}$ 2, Soil Science Society of America, Madison, $744 \quad$ pp233-277.

745 Meyer, M.C., McLendon, T., 1997. Phytotoxicity of depleted uranium on three grasses

746 characteristic of different successional stages. J. Environ. Qual. 26, 748-752.

747 Mihalik, J., Henner, P., Frelon, S., Camilleri V., Février, L., 2012. Citrate assisted

748 phytoextraction of uranium by sunflowers: study of fluxes in soils and plants and resulting 749 intra-planta distribution of Fe and U. Env. Exp. Bot. 77, 249-258.

750 Mimmo, T., Hann, S., Jaitz, L., Cesco, S., Gessa, C.E., Puschenreiter, M., 2011. Time and 751 substrate dependent exudation of carboxylates by Lupinus albus L. and Brassica napus L. 752 Plant Physiol. Biochem. 49, 1272-1278.

753 Misson, J., Henner, P., Morello, M., Floriani, M., Wu, T.-D., Guerquin-Kern, J.-L., Février, 754 L., 2009. Use of phosphate to avoid uranium toxicity in Arabidopsis thaliana leads to 
755 alterations of morphological and physiological responses regulated by phosphate

756 availability. Environ. Exp. Bot. 67, 353-362.

757 Oburger, E., Jones, D.L., Wenzel, W.W., 2011a. Phosphorus saturation and pH differentially

758 regulate the efficiency of organic acid anion-mediated $\mathrm{P}$ solubilisation mechanisms in soil.

759 Plant Soil 341, 363-382.

760 Oburger, E., Leitner, D., Jones, D.L., Zygalakis, K.C., Schnepf, A., Roose, T., 2011 b.

761 Adsorption and desorption dynamics of citric acid anions in soil. Eur. J. Soil Sci. 62, 733-

762742.

763 OECD., 2000. Absorption-desorption using a batch equilibrium method. Test guidelines 106,

764 Organisation for Economic Co-operation and Development. Updated Guideline, January, $76521^{\text {st }}, 2000$.

766 Parfitt, R.J., Atkinson, R.J., Smart, R.S.C., 1975. The mechanism of phosphate fixation by 767 iron oxides. Soil Sci. Soc. Am. J. 39(5), 837-841.

768 Payne, T.E., Davis, J.A., Waite, T.D., 1996. U sorption on ferrihydrite- effects of phosphate 769 and humic acid. Radiochim. Acta. 74, 239-243.

770 Pfeifer, H.-R., Vust, M., Meisser, N., Doppenberg, R., Croci Torti, R., Domergue, F.-L., 771 Keller, K., Hunziker, J., 1994. Uranium-enrichment in soils and plants in the vicinity of a 772 pitchblende vein at La Creuzaz/Les Marécottes (W of Martigny, Valais, Switzerland). 773 Eclogae Geol. Helv., 87/2, 491-501.

774 R Development Core Team, 2011. The R project for statistical computing. URL http://www.r775 project.org.

776 Ragnarsdottir, K.V., Charlet, L., 2000. Uranium behaviour in natural environments. In:

777 Cotter-Howells, J.D., Campbell, L.S., Valsami-Jones, E., Batchelder, M. (Eds.)

778 Environmental Mineralogy: Microbial interactions, Anthropogenic Influences,

779 Contaminated Land and Waste Management. Vol. 9 of Mineralogical Society Series. 
780 Mineralogical Society of Great Britainb and Ireland, Twickenham, United Kingdom, pp $781 \quad 245-289$.

782 Raicevic, S., Wright, J.V., Velkojic, V., Conca, J.L., 2006. Theoretical stability assessment of 783 uranyl phosphates and apatites: selection of amendments for in situ remediation of uranium. 784 Sci. Tot. Environ. 355, 12-24.

785 Ribera, D., Labrot, F., Tisnerat, G., Narbonne, J.F., 1996. Uranium in the environment: 786 occurrence, transfer, and biological effects. Rev. Environ. Contam. Toxicol. 146, 53-89. 787 Romero Guzman, E.T., Esteller Alberich, M.V., Ordonez Regil, E., 2002. Uranium and 788 phosphate behavior in the vadose zone of a fertilized corn field. J. Radioanal. Nucl. Chem. $789 \quad 254(3), 509-517$.

790 Römheld, V., 1987. Different strategies for iron acquisition in higher plants. Physiol.

$791 \quad$ Plantarum 70, 231-234.

792 RP, 2008. Référentiel pédologique 2008, Baize, D., Girard, M.-C. (Coord.à, AFES, Editions 793 Quae.

794 Shahandeh, H., Hossner, L.R., 2002. Enhancement of uranium phytoaccumulation from 795 contaminated soils. Soil Sci., 167(4), 269-280.

796 Sheppard, S.C., Evenden, W.G., Anderson, A.J., 1992. Multiple assays of uranium toxicity in 797 soil. Environ. Toxicol. Water Qual.: Int. J. 7, 275-294.

798 Sheppard, S.C., Sheppard, M.I., Gallerand, M.-O., Sanipelli, B., 2005. Derivation of 799 ecotoxicity thresholds for uranium. J. Environ. Radioactiv. 79, 55-83.

800 Stojanović, M.D., Stevanović, D.R., Milojković, J.V., Grubišić, M.S., Ileš D.A., 2009.

801 Phytotoxic effect of the uranium on the growing up and development of the plant of corn.

802 Water Air Soil Pollut. 209, 401-410. 
803 Straczek, A., Wanninjn, J., Van Hees M., Thijs, H., Thiry, Y. 2009. Tolerance of hairy roots

804 of carrots to U chronic exposure in a standardized in vitro device. Environ. Exp. Bot. 65(1), $805 \quad 82-89$

806 Straczek, A., Duquene, L., Wegrzynek, D., Chinea-Cano, E., Wannijn, J., Navez, J.,

807 Vandenhove, H., 2010. Differences in U root to shoot translocation between plant species

808 explained by U distribution in roots. J. Environ. Radioactiv., 101(3), 258-266)

809 Tailliez, A., Pierrisnard, S., Camilleri, V., Keller, C., Henner, P., 2013. Do rhizospheric

810 processes linked to $\mathrm{P}$ nutrition participate in $\mathrm{U}$ absorption by Lupinus albus grown in

811 hydroponics? J. Environ. Radioactiv., 124, 255-265.

812 Teramage, M.T., Carasco, L., Orjollet, D., Coppin F., 2017. Radiocesium input forms and its 813 extractability in Fukushima forest soils. Under review by Soil Biol. Biochem.

814 Vance, C.P., Uhde-Stone, C., Allan, D.L., 2003. Phosphorus acquisition and use: critical 815 adaptations by plants for securing a nonrenewable resource. New Phytol. 157, 423-447.

816 Vandenhove, H., Cuypers, A., Van Hees, M., Koppen, G., Wannijn, J., 2006a. Oxidative 817 stress reactions induced in beans (Phaseolus vulgaris) following exposure to uranium. Plant 818 Physiol. Biochem. 44, 795-805.

819 Vandenhove, H., Van Hees, M., Wouters, K., Wannijn, J., Wang, L., 2006b. Can we predict 820 uranium bioavailability based on soil parameters? Part 2: Soil solution uranium concentration 821 is not a good bioavailability index. Environ. Pollut. 145(2), 577-586.

822 Vanhoudt, N., Vandenhove, H., Smeets, K., Remans, T., Van Hees, M., Wannijn, J.,

823 Vangronsveld, J., Cuypers, A., 2008. Effects of uranium and phosphate concentrations on 824 oxidative stress related responses induced in Arabidopsis thaliana. Plant Physiol. Biochem. $82546,987-996$.

826 Viehweger, K., Geipel, G. 2010. Uranium accumulation and tolerance in Arabidopsis halleri 827 under native versus hydroponic conditions. Environ. Exp. Bot. 69, 39-46. 
828 Waite, T.D., Davis, J.A., Payne, T.E., Waychunas, G.A., Xu, N., 1994. U(VI) sorption to

829 ferrihydrite: application of the surface complexation model. Geochim. Cosmochim. Acta. 58, $830 \quad 5465-5478$.

831 
832

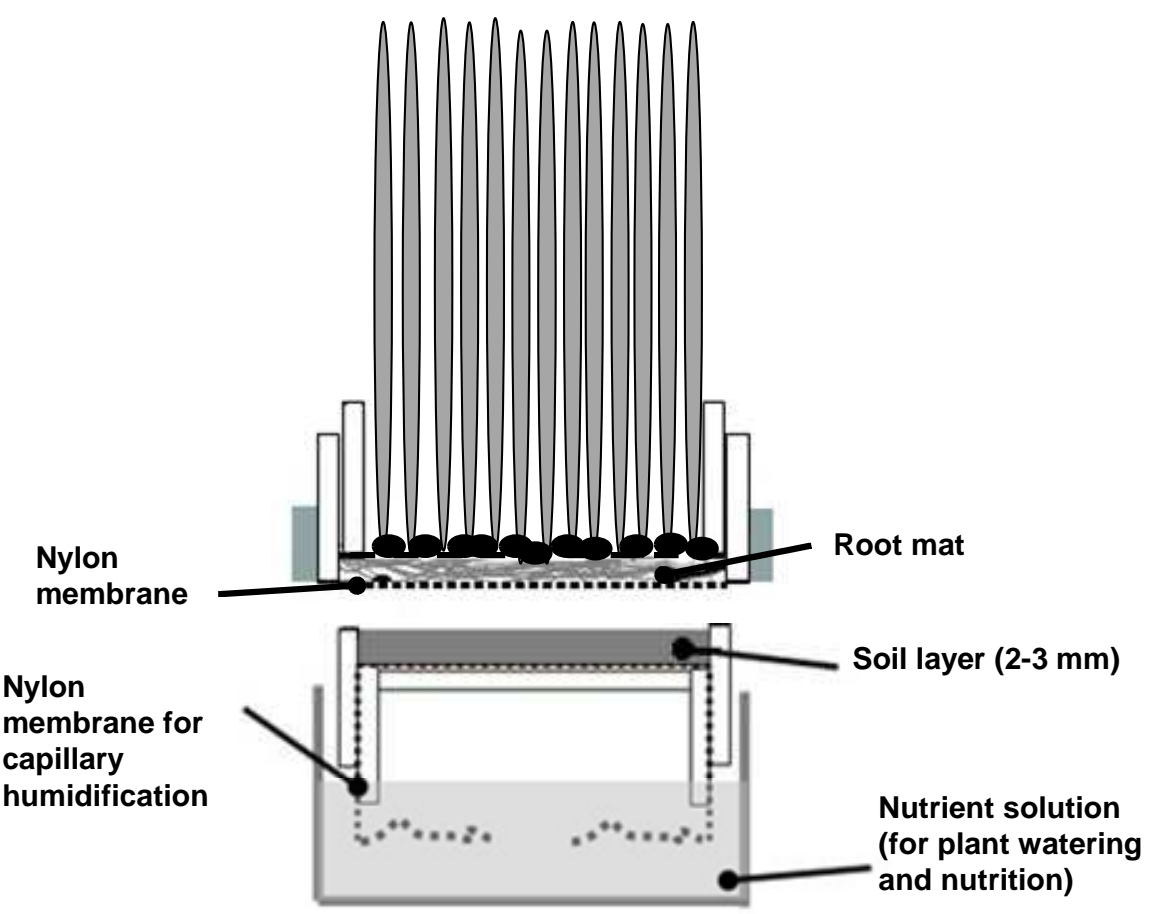

833 Figure 1: Rhizotest device.

834

835 


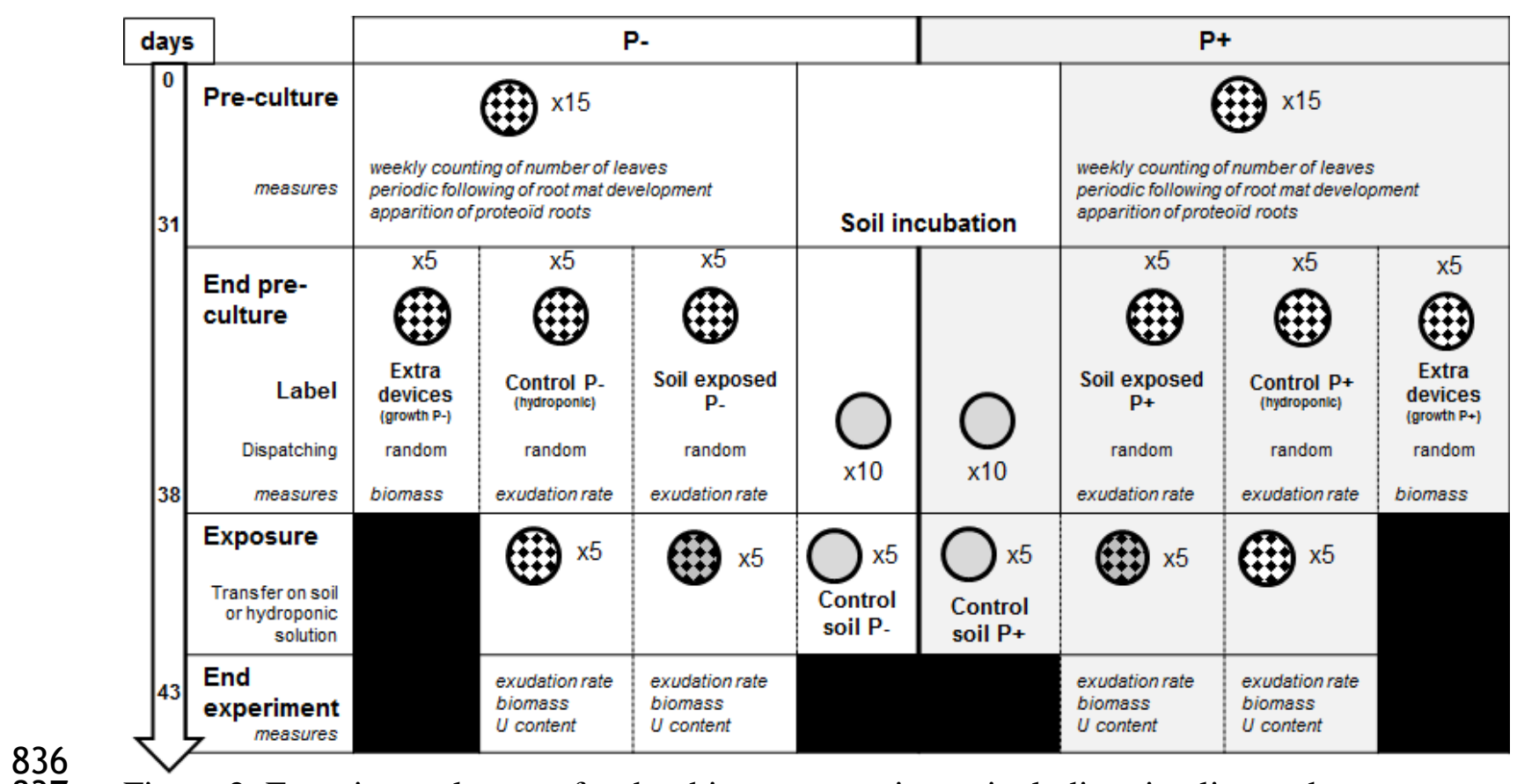

837 Figure 2: Experimental set-up for the rhizotest experiment including timeline and measures. 

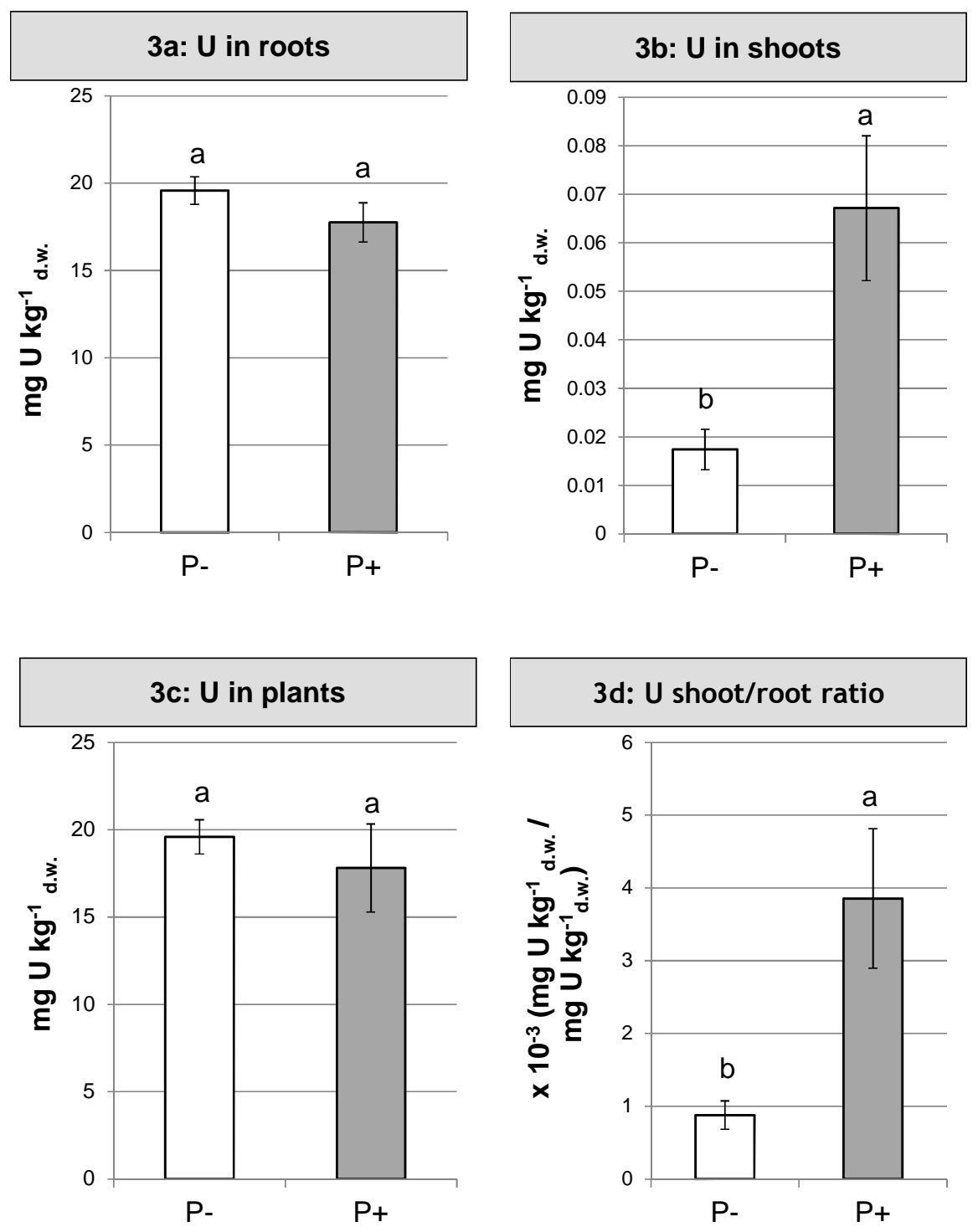

839

840 Figure 3: Accumulation of $U$ in lupine plants after 5-day exposure to soil 1 in the rhizotest

841 design. $3 a$ : $\mathrm{U}$ in roots (in $\mathrm{mg} \mathrm{U}$ per $\mathrm{kg}$ dry matter roots); $3 \mathrm{~b}$ : $\mathrm{U}$ in shoots (in $\mathrm{mg}$ per $\mathrm{kg}$ dry

842 matter shoots); 3c: U plants (in $\mathrm{mg}$ per $\mathrm{kg}$ dry matter shoots + roots); $3 \mathrm{~d}$ : ratio of $\mathrm{U}$

843 accumulation in shoot vs root. Mean of 5 replicates \pm s.e. Letters: differences between $\mathrm{P}$

844 treatment, ANOVA, $\mathrm{p}<0.001$. 

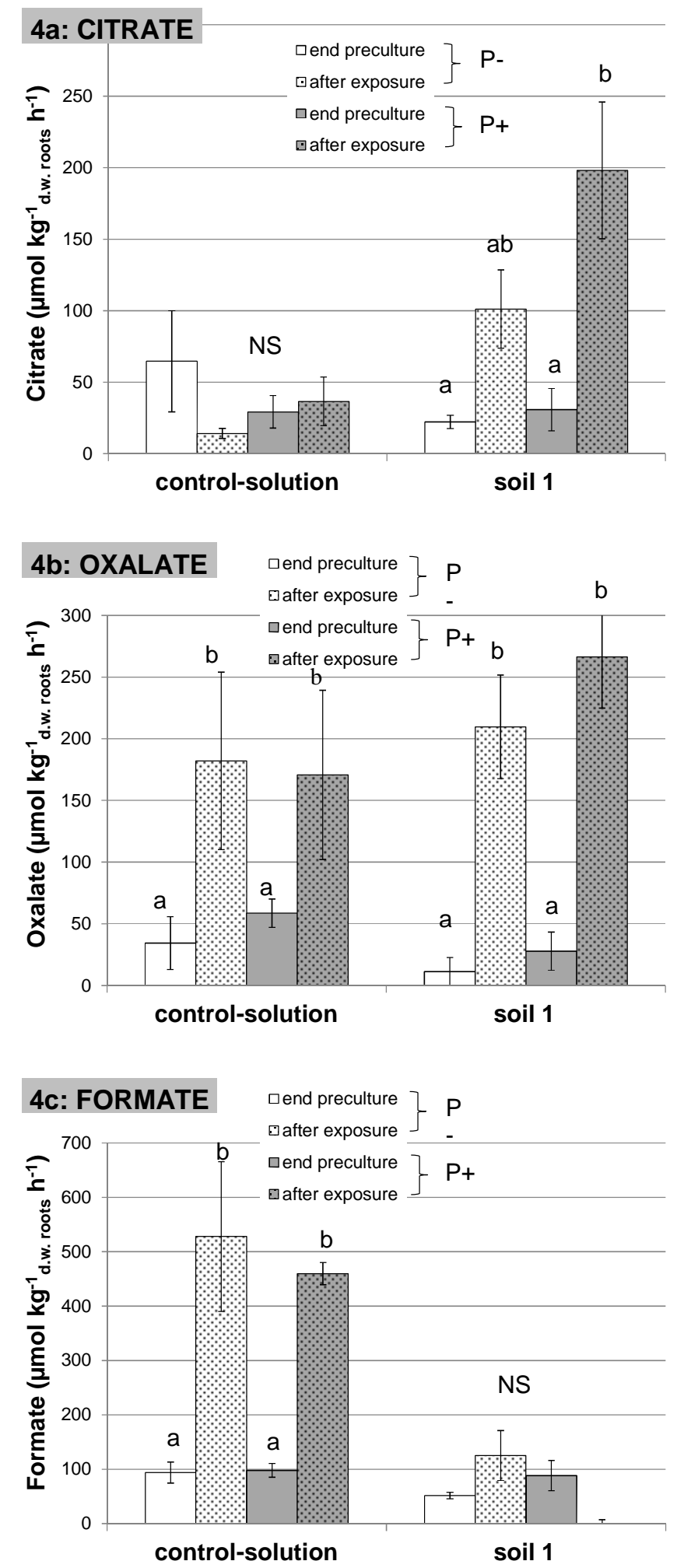

850 Figure 4: Root exudation of citrate (4a), oxalate (4b) and formate (4c) on the rhizotest design

851 by lupine plants at the end of the pre-culture period and after 5 day-exposure to soil 1 or

852 solution as control (mean of 5 replicates \pm standard error). Letters: results of 1-factor

853 (condition) ANOVA for each kind of rhizotests (hydroponics/soil 1) $(\mathrm{P}<0.05)$. 


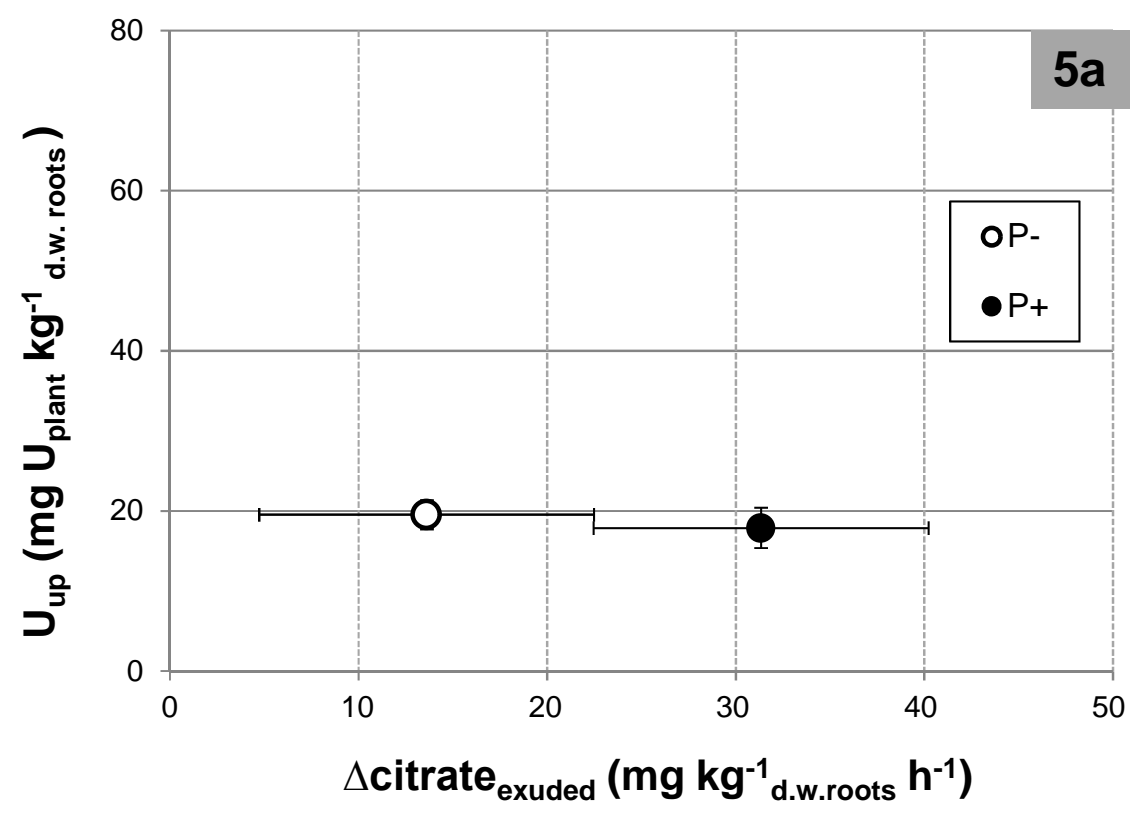

854

855

856

857

858

859

860

861

862

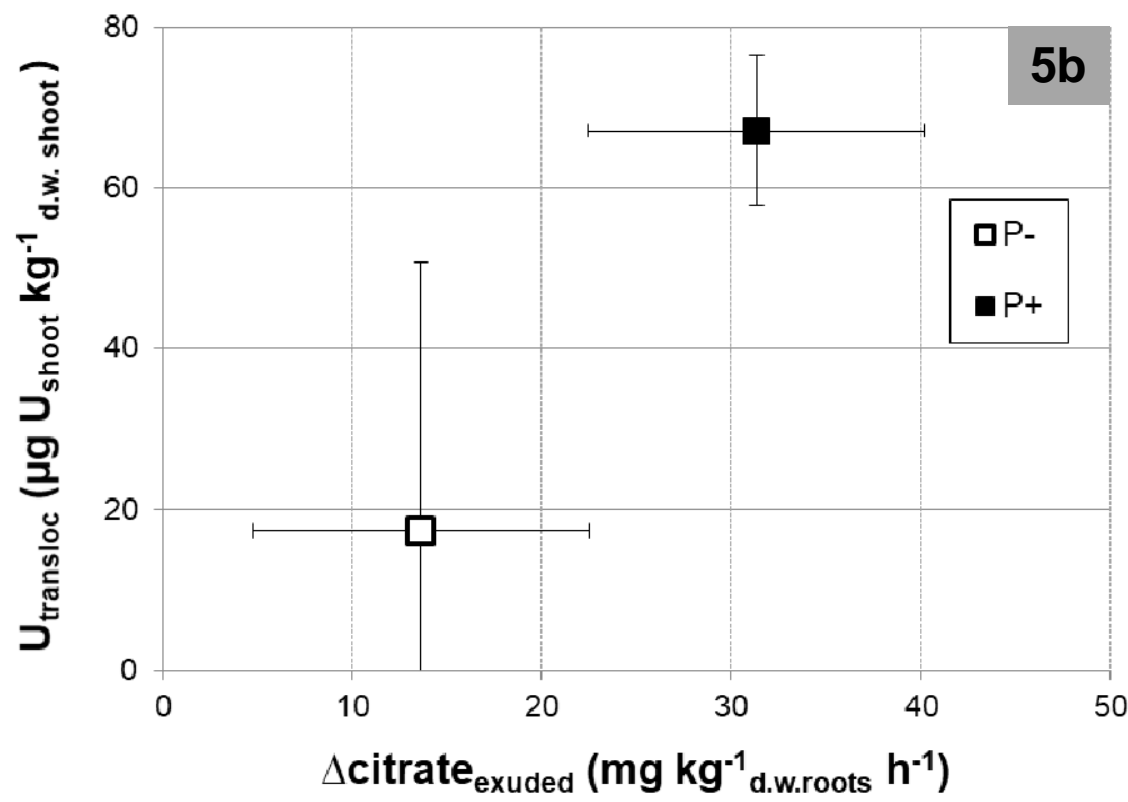

863

864 Figure 5: Results of $U$ uptake (total $U$ in plant as related to dry mass of roots, $m g U_{\text {plant }} \mathrm{kg}^{-1}$

865 roots d.w., 5a) and $\mathrm{U}$ translocated to shoots ( $\mu \mathrm{g} \mathrm{U} \mathrm{kg}^{-1}$ shoots d.w., 5b) as a function of $\mathrm{P}$ level and

866 variation in citrate exudation rate measured between beginning and end of exposure to soil 1

867 ( $\Delta$ citrate $\left._{\text {exuded}}\right)$. Mean of 5 rhizotests \pm s.e. 


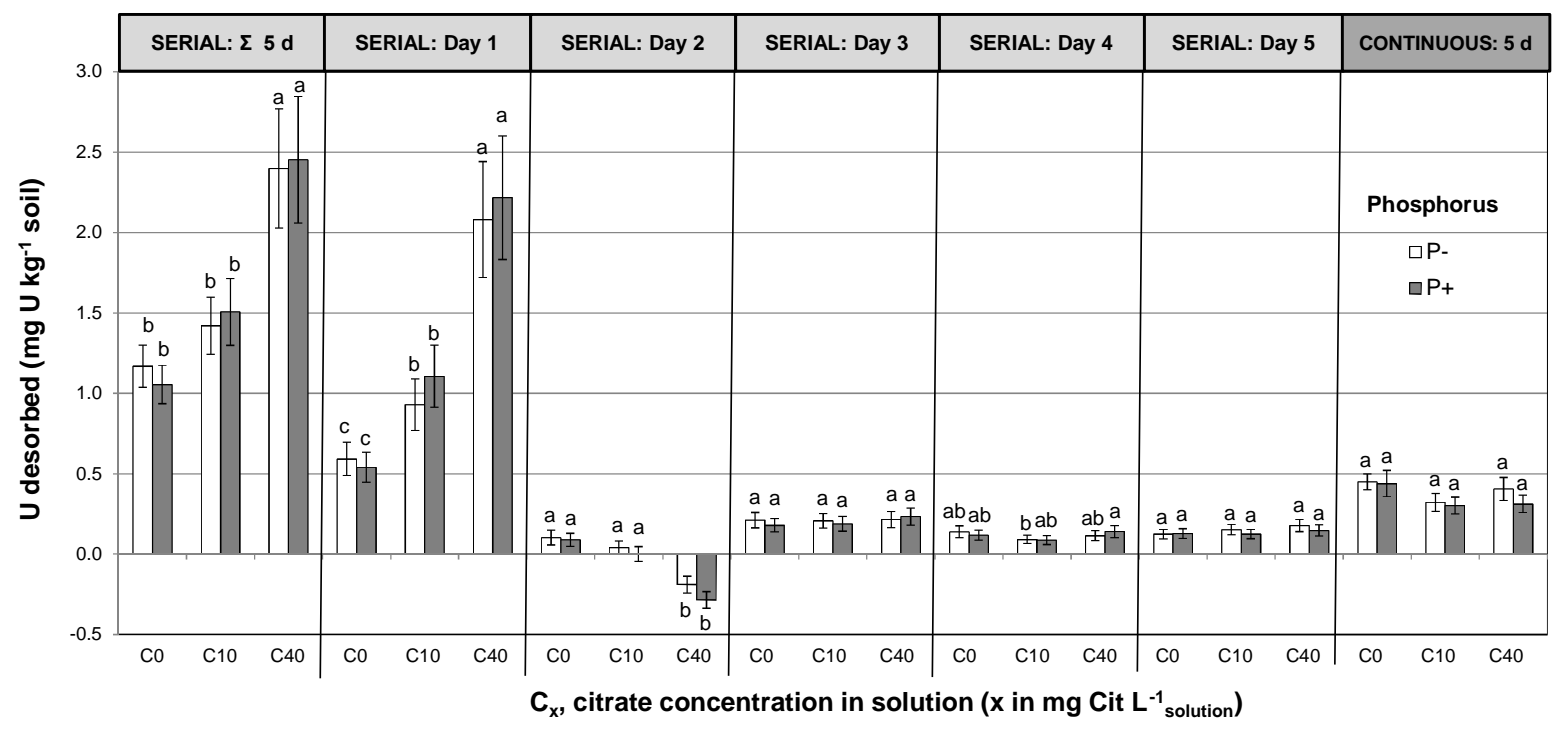

871 Figure 6: U desorbed from soil 1 as a function of time either for a 5-day continuous extraction,

872 or a 5-day serial extraction (with change of solution every day), $\mathrm{P}$ status of the solution and

873 citrate concentration. Mean of 3 replicates \pm s.e. Letters: ANOVA for each day, $\mathrm{p}<0.01$.

874 Values may be positive (desorption) or negative (apparent sorption). 

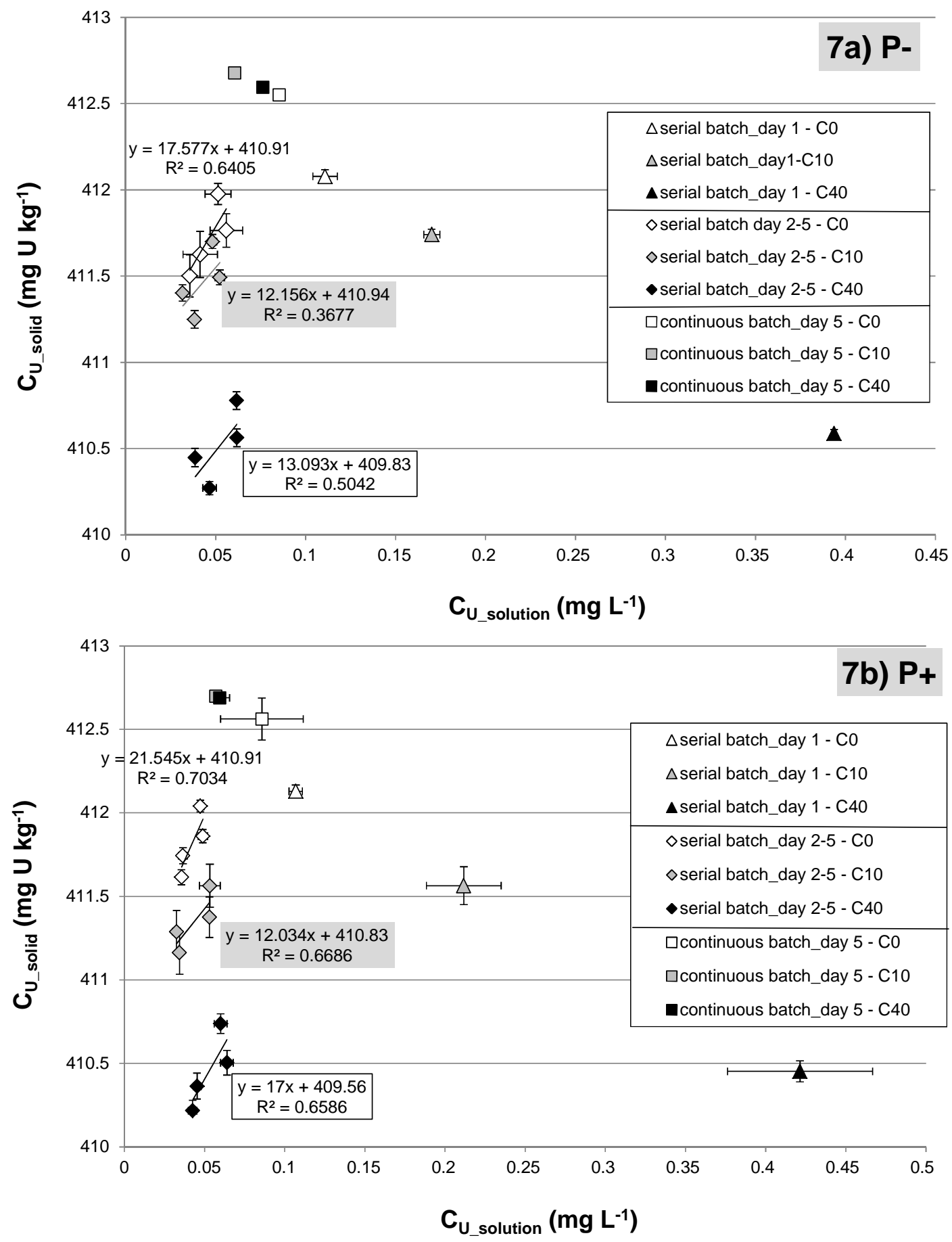

878 Figure 7: $\mathrm{C}_{\mathrm{U}_{-} \text {total_solid }}$ as a function $\mathrm{C}_{\mathrm{U}_{-} \text {solution }}$ at the end of each step of serial vs continuous

879 batch for the a) $\mathrm{P}$ - and b) $\mathrm{P}+$ conditions and all citrate concentrations. Mean of 3 replicates \pm s.e. 


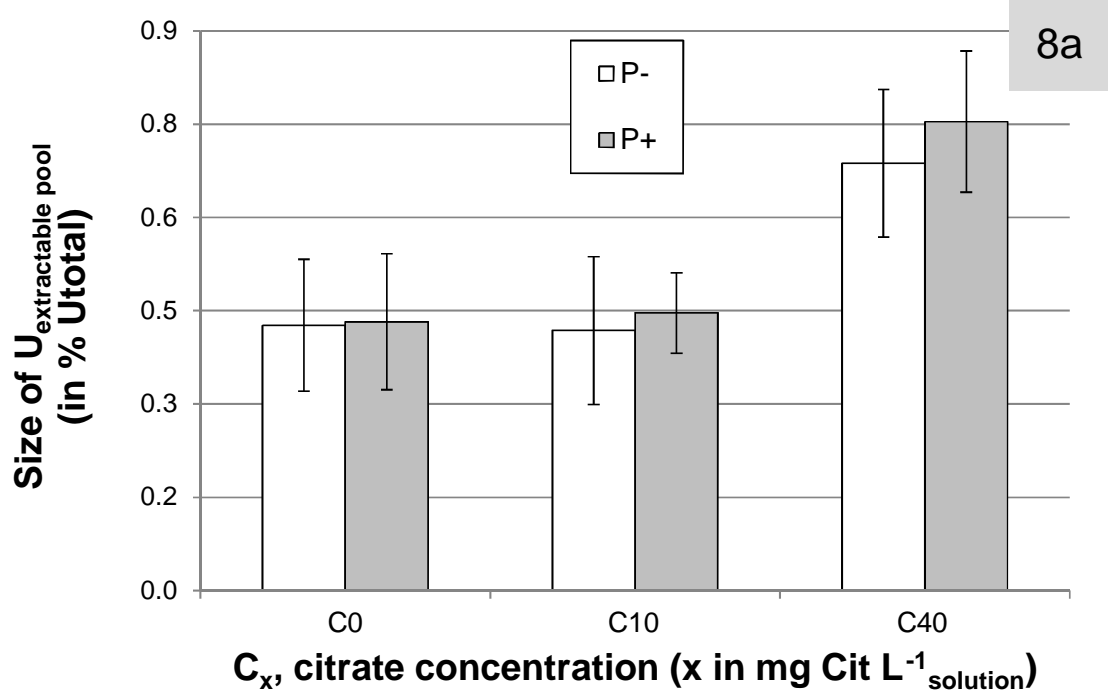

883

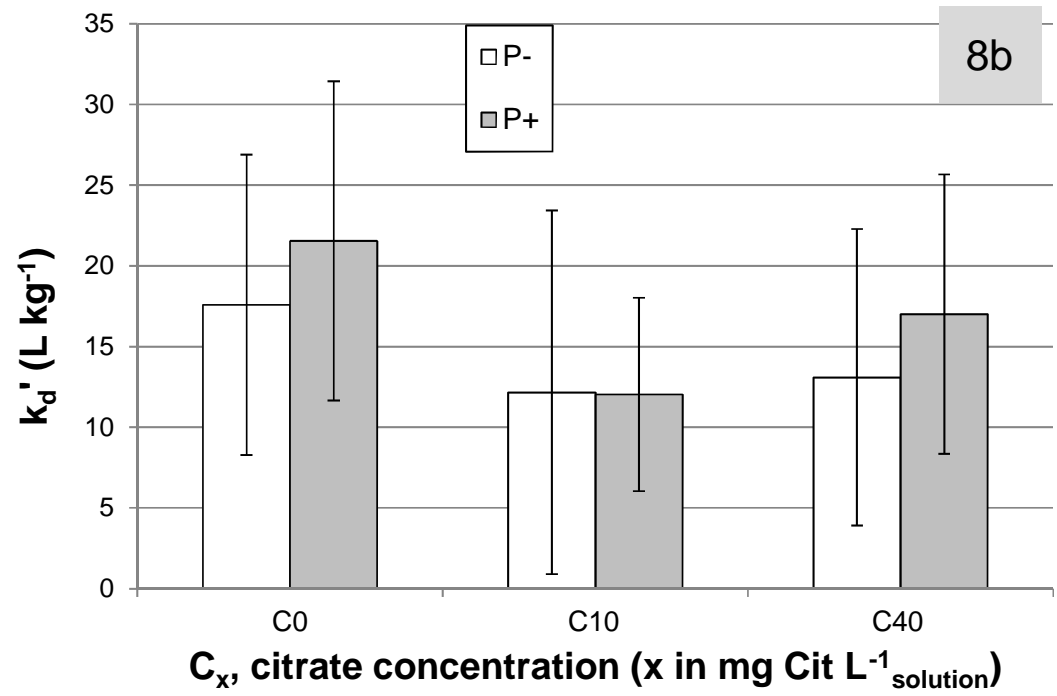

885 Figure 8: 8a-Size of U extractable pool (\% of total soil $\mathrm{U}$ ) and $8 \mathrm{~b}-\mathrm{k}_{\mathrm{d}}$ ' as a function of soil, $\mathrm{P}$ 886 and citrate conditions (estimate \pm s.e.). 

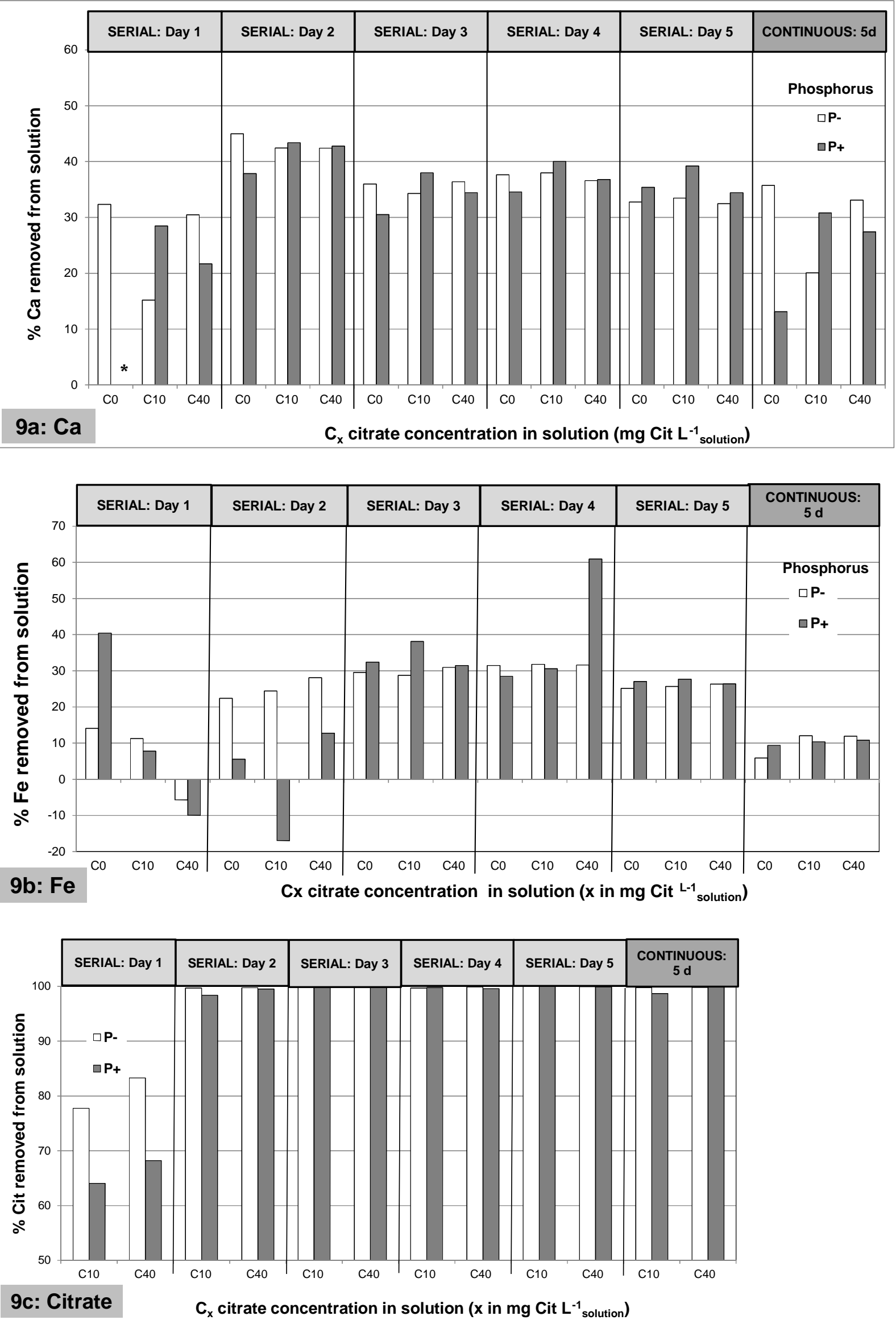


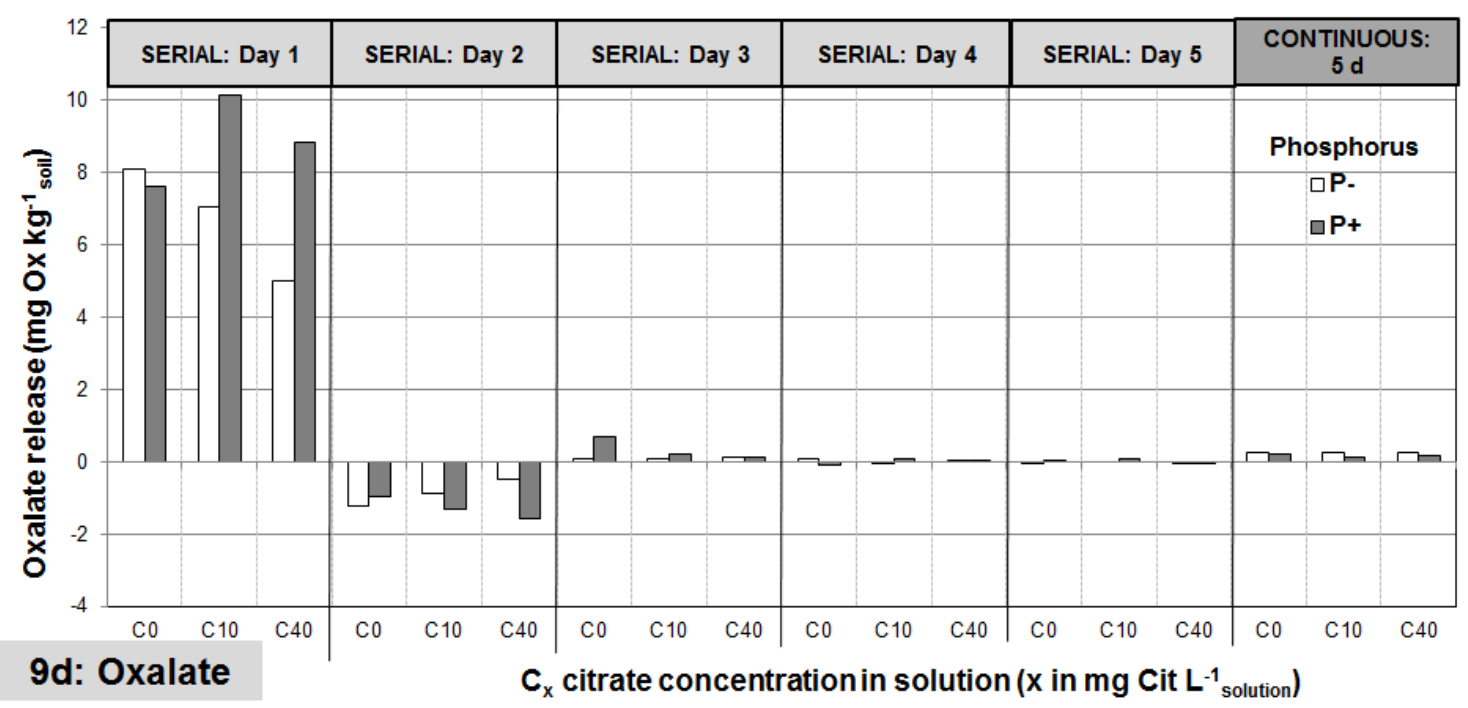

894 Figure 9: Calcium (9a), iron (9b) and citrate (9c) removal from solution and oxalate (9d) 895 release in solution during each step as a function of citrate concentration in solution 896 (C0/C10/C40 conditions), phosphorus status (P- or P+ for 1 and $100 \mu \mathrm{M}$ P respectively) and 897 type of batch (serial or continuous) Contrary to $U$ and oxalate, $\mathrm{Ca}, \mathrm{Fe}$ and citrate are present 898 in the initial solution, thus dynamics was calculated as the difference between final and initial 899 solution concentration. Thus values may be positive (decrease compared to initial 900 concentration) or negative (apparent release) depending which process was dominant during 901 the corresponding period (24h or 5 days).* aberrant value. 
Table 1: Soil characteristics.

\begin{tabular}{|c|c|c|}
\hline Characteristics & Units & Soil 1 \\
\hline Clay $(<2 \mu \mathrm{m})$ & $\mathrm{g} \mathrm{kg}^{-1}$ & 183 \\
\hline Loam $(2-50 \mu \mathrm{m})$ & $\mathrm{g} \mathrm{kg}^{-1}$ & 358 \\
\hline Sand $(50-2000 \mu \mathrm{m})$ & $\mathrm{g} \mathrm{kg}^{-1}$ & 459 \\
\hline Organic matter & $\mathrm{g} \mathrm{kg}^{-1}$ & 119.5 \\
\hline $\mathrm{C} / \mathrm{N}$ & & 15.8 \\
\hline $\mathrm{pH}-\mathrm{H}_{2} \mathrm{O}$ & & 4.97 \\
\hline CEC Metson & $\mathrm{cmol}+\mathrm{kg}^{-1}$ & 15.5 \\
\hline CEC cobaltihexamine & $\mathrm{cmol}+\mathrm{kg}^{-1}$ & 5.73 \\
\hline Total U & $\mathrm{mg} \mathrm{kg}^{-1}$ & 413 \\
\hline Soluble $\mathrm{U}^{\mathrm{a}}$ & $\mathrm{mg} \mathrm{kg}^{-1}$ & 2.9 \\
\hline Total Fe & $\mathrm{g} \mathrm{kg}^{-1}$ & 43.4 \\
\hline Fe oxalate & $\%$ & 24.3 \\
\hline Fe Mehra-Jackson & $\%$ & 45.6 \\
\hline Total P & $\mathrm{g} \mathrm{kg}^{-1}$ & 2.2 \\
\hline Olsen P & $\mathrm{g} \mathrm{kg}^{-1}$ & 0.019 \\
\hline \multirow{3}{*}{ Exchangeable cations } & $\mathrm{K} \mathrm{g} \mathrm{kg}^{-1}$ & 0.22 \\
\hline & $\mathrm{Ca} \mathrm{g} \mathrm{kg}^{-1}$ & 0.65 \\
\hline & $\mathrm{Mg} \mathrm{g} \mathrm{kg}^{-1}$ & 0.08 \\
\hline \multirow[t]{2}{*}{ Soluble elements $^{b}$} & $\mathrm{P} \mathrm{g} \mathrm{kg}^{-1}$ & $<0.002$ \\
\hline & $\mathrm{N} \mathrm{mg} \mathrm{kg}^{-1}$ & 48.94 \\
\hline \multirow{2}{*}{ (in $\mathrm{H}_{2} \mathrm{O}$ ) } & $\mathrm{S} \mathrm{mg} \mathrm{kg}{ }^{-1}$ & 9.99 \\
\hline & $\mathrm{C}_{\text {org }} \mathrm{mg} \mathrm{kg}^{-1}$ & 670 \\
\hline
\end{tabular}

$904{ }^{\mathrm{a}}$ Measured after $24 \mathrm{~h}$ desorption in batch system, with $3 \mathrm{~g}$ of soil and $30 \mathrm{~mL}$ water.

$905{ }^{\mathrm{b}}$ INRA Method, water extraction, m/v 1/5, quantification in the extract by FAAS (Flame Atomic Absorption 906 Spectrometry). 
909 Supplementary material

910 S1: Biomass recorded during the rhizotest experiment

911

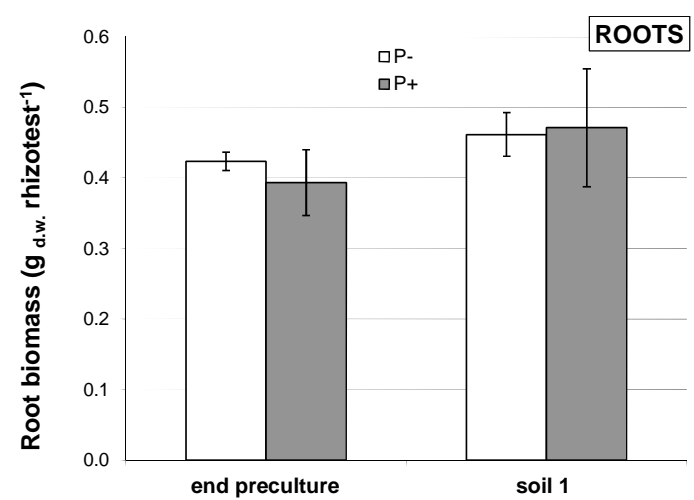

912

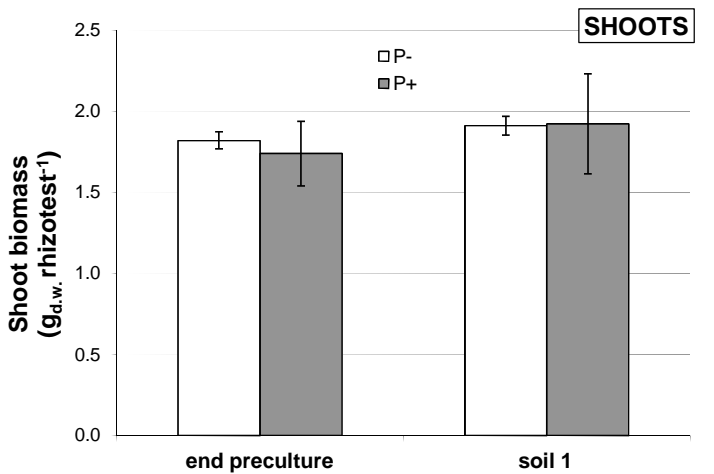

913 Figure S1 : Rhizotest: biomass of lupine plants

914 


\section{Supplementary material}

916 S2: Evapotranspiration on rhizotests - link with U uccumulation

917 S2-1: Evapotranspiration of lupine on both soils was of the same order in both P condition $918(175 \pm 26 \mathrm{ml}$ in 5 days in $-\mathrm{P}$ and $169 \pm 10 \mathrm{ml}$ in $+\mathrm{P})$.

919
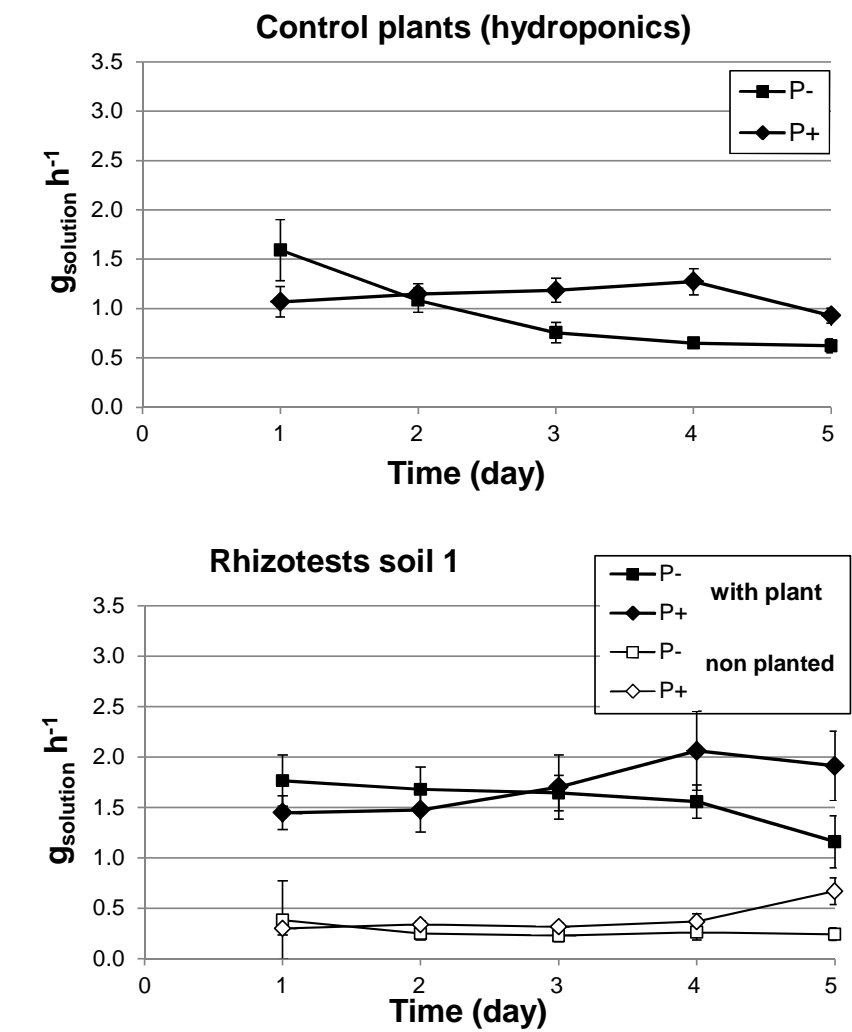

920

921 Figure S2-1: Solution fluxes in the rhizotest device (mean of 5 replicates \pm standard error). 
923 S2-2: U accumulation as related to water flux through the rhizotest

924

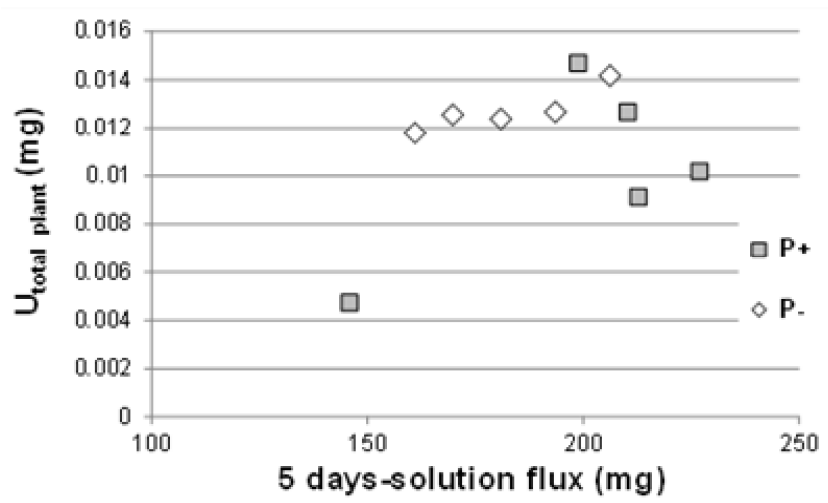

925 Figure S2-2: Stock of U (mg) accumulated in lupine plant after 5-days exposure to soil 1 in

926 the rhizotest design as a function of the corresponding flux of solution across the rhizotest.

927

928 


\section{Supplementary material}

\section{S3: Additional characterization of the soil samples}

931 To get insights in the possible different $U$ forms (hotspots vs others) in soil which could either

932 highlight results detailed in this document and explain differences obtained with the similar

933 soil those results are displayed in the supplementary material, complementary analyses were

934 performed. While X-Ray diffraction did not detect any specific U-bearing minerals pointing

935 to a homogeneous $U$ contamination, $X$-ray $\mu$ fluorescence analyses performed on X-Ray

936 Analytical microscope HORIBA Jobin Yvon XGT 7000 (data not shown) indicated a

937 background level of $0.3 \% \mathrm{U}$ with some $\mathrm{U}$-enriched zones with up to $1.5 \% \mathrm{U}$, which could be

938 responsible for the variability observed in the results. In addition, these U hotspots showed

939 concomitant lower $\mathrm{Fe}, \mathrm{Mn}$ and $\mathrm{S}$ concentrations and higher $\mathrm{K}$ and $\mathrm{Si}$ concentrations, as

940 compared to background suggesting that $U$ was preferentially associated with new minerals

941 containing K and Si in accordance with the observations made by Allard et al. (1999). These

942 analyses may again suggest that there are different U "bearing-phases", characterized by

943 different reactivity with citrate leading to variable U lability in the soil(s). The U-available

944 bearing phase dissolved by citrate is different from the U-unavailable phase, quantitatively

945 more important and the only one detectable by X-ray fluorescence. 


\section{Supplementary material}

\section{S4: Results obtained on soil 2}

949 During the study, 4 soils were collected at different distances from the pechblende vein, in 950 order to get a naturally-produced U gradient in the "same" soil or at least soils with close 951 properties. The experimental plan was too ambitious to be displayed on the 4 soils, thus only 952 two were chosen. The second soil (soil 2) had similar properties (see table below) but a higher $953 \mathrm{U}$ content (500 $\mathrm{mg} \mathrm{U} \mathrm{kg}^{-1}$ soil) and was situated downwards soil 1 although the gradient was 954 supposed to be related to distance from the vein. This could have signed a peculiar behavior 955 regarding speciation, migration or (bio) availability. Thus, the complete experimental set up 956 described for soil 1 was applied to soil 2. Results were equivalent to those of soil 1 are thus 957 not detailed but displayed in supplementary material as they validate all statements made in 958 this document.

959 1. Soil 2 properties

\begin{tabular}{|c|c|c|}
\hline Characteristics & Units & Soil 2 \\
\hline Clay $(<2 \mu \mathrm{m})$ & $\mathrm{g} \mathrm{kg}^{-1}$ & 141 \\
\hline Loam $(2-50 \mu \mathrm{m})$ & $\mathrm{g} \mathrm{kg}^{-1}$ & 285 \\
\hline Sand $(50-2000 \mu \mathrm{m})$ & $\mathrm{g} \mathrm{kg}^{-1}$ & 574 \\
\hline Organic matter & $\mathrm{g} \mathrm{kg}^{-1}$ & 109.6 \\
\hline $\mathrm{C} / \mathrm{N}$ & & 17.8 \\
\hline $\mathrm{pH}-\mathrm{H}_{2} \mathrm{O}$ & & 5.26 \\
\hline CEC Metson & $\mathrm{cmol}+\mathrm{kg}^{-1}$ & 14.3 \\
\hline CEC cobaltihexamine & $\mathrm{cmol}+\mathrm{kg}^{-1}$ & 7.2 \\
\hline Total U & $\mathrm{mg} \mathrm{kg}^{-1}$ & 525 \\
\hline Soluble $\mathrm{U}^{\mathrm{a}}$ & $\mathrm{mg} \mathrm{kg}^{-1}$ & 3.4 \\
\hline Total Fe & $\mathrm{g} \mathrm{kg}^{-1}$ & 46.8 \\
\hline Fe oxalate & $\%$ & 17.7 \\
\hline Fe Mehra-Jackson & $\%$ & 43.4 \\
\hline Total P & $\mathrm{g} \mathrm{kg}^{-1}$ & 2.7 \\
\hline Olsen $\mathrm{P}$ & $\mathrm{g} \mathrm{kg}^{-1}$ & 0.022 \\
\hline \multirow{3}{*}{ Exchangeable cations } & $\mathrm{Kg} \mathrm{kg}^{-1}$ & 0.24 \\
\hline & $\mathrm{Cag} \mathrm{kg}{ }^{-1}$ & 1.08 \\
\hline & $\mathrm{Mg} \mathrm{g} \mathrm{kg}^{-1}$ & 0.14 \\
\hline \multirow{4}{*}{$\begin{array}{l}\text { Soluble elements } \\
\left(\text { in } \mathrm{H}_{2} \mathrm{O}\right)\end{array}$} & $\mathrm{P} \mathrm{g} \mathrm{kg}^{-1}$ & $<0.002$ \\
\hline & $\mathrm{N} \mathrm{mg} \mathrm{kg}$ & 47.33 \\
\hline & $\mathrm{S} \mathrm{mg} \mathrm{kg}^{-1}$ & 15.37 \\
\hline & $\mathrm{C}_{\text {org }} \mathrm{mg} \mathrm{kg}^{-1}$ & 1008 \\
\hline
\end{tabular}

$960{ }^{\mathrm{a}}$ Measured after $24 \mathrm{~h}$ desorption in batch system, with $3 \mathrm{~g}$ of soil and $30 \mathrm{~mL}$ water.

$961{ }^{\mathrm{b}}$ INRA Method, water extraction, m/v 1/5, quantification in the extract by FAAS (Flame 962 Atomic Absorption Spectrometry). 
964 Biomasses recorded on soil 2 are equivalent to those recorded on soil 1.

965

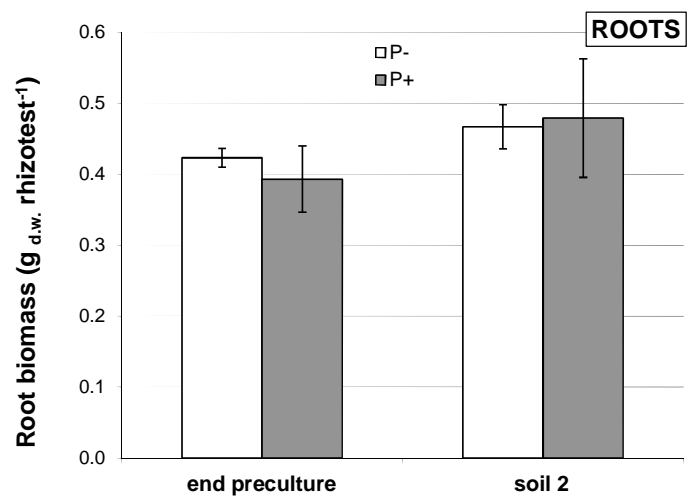

966

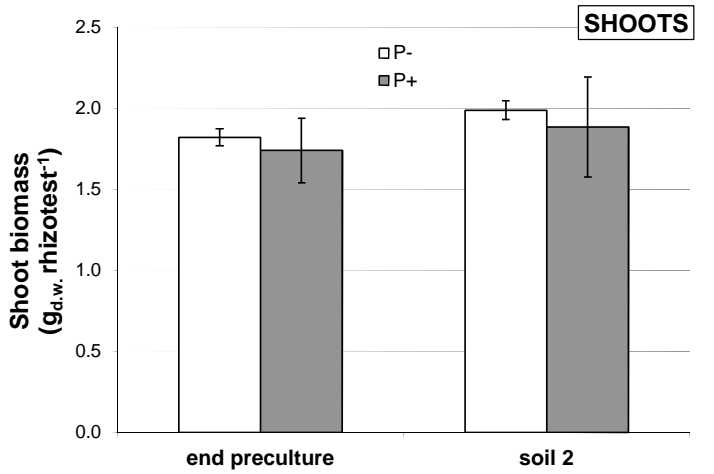

967 Figure S4-1: Biomass of lupine plants recorded for rhizotest with soil 2.

968

969

\section{Evapotranspiration}

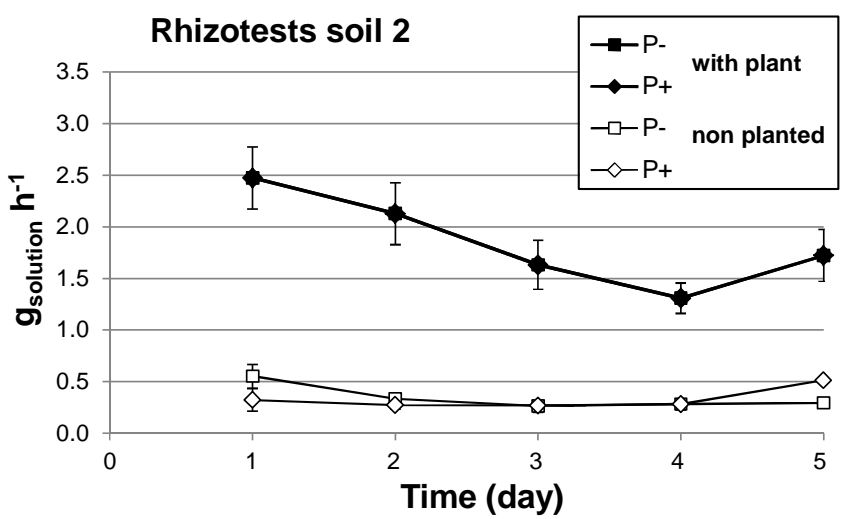

Figure S4-2: Evapotranspiration of rhizotests of soil 2 as a function of $\mathrm{P}$ treatment and type of 972 rhizotest. 

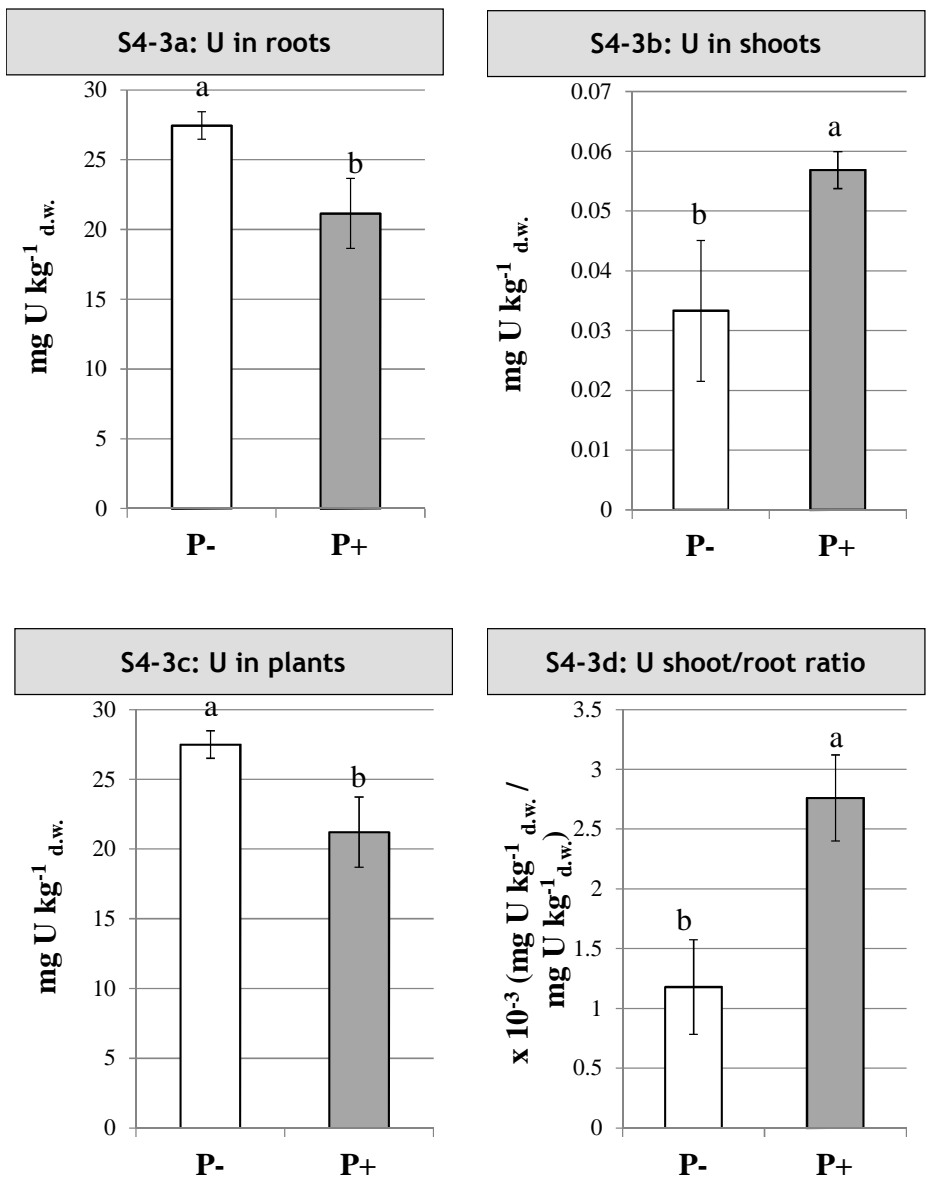

985 Figure S4-3: Accumulation of $U$ in lupine plants after 5-day exposure to soil 2 in the rhizotest 986 design. 3a: $\mathrm{U}$ in roots (in $\mathrm{mg} \mathrm{U}$ per $\mathrm{kg}$ dry matter roots); $3 \mathrm{~b}$ : $\mathrm{U}$ in shoots (in $\mathrm{mg}$ per $\mathrm{kg}$ dry 987 matter shoots); 3c: U plants (in $\mathrm{mg}$ per $\mathrm{kg}$ dry matter shoots + roots); $3 \mathrm{~d}$ : ratio of $\mathrm{U}$ 988 accumulation in shoot vs root. Mean of 5 replicates \pm s.e. Letters: differences between $\mathrm{P}$ 989 treatment, ANOVA, $\mathrm{p}<0.001$. 
991 Results (Fig. S4-3) are in adequation with those recorded on soil 1. The total U uptake is 992 slightly lower than on soil 1 but the difference between $\mathrm{P}$ - and $\mathrm{P}+$ for translocation to root is 993 higher than on soil 1. Contrary to soil 1 , there seems to be a small relation between $U$ 994 accumulated and water flux though the rhizotest (Figure S4-4).

995

996

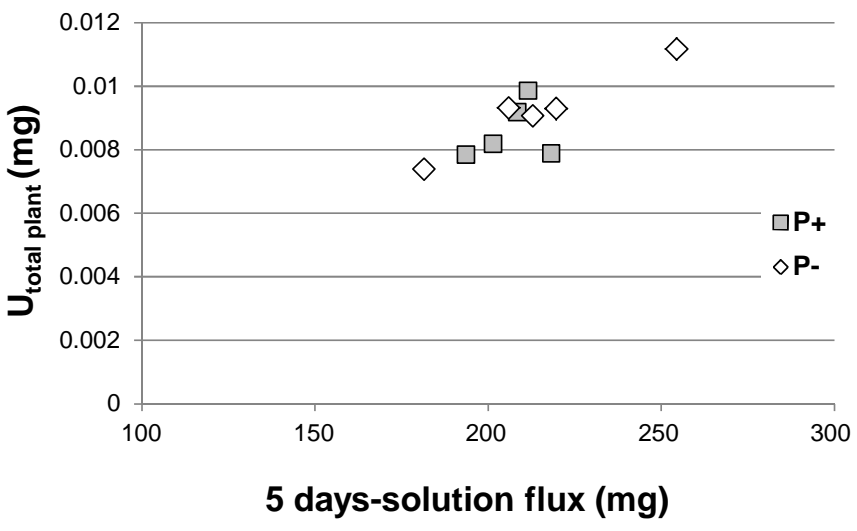

998 Figure S4-4: Stock of U (mg) accumulated in lupine plant after 5-days exposure to soil 2 in 999 the rhizotest design as a function of the corresponding flux of solution across the rhizotest.

1000

1001

\section{Exudation}

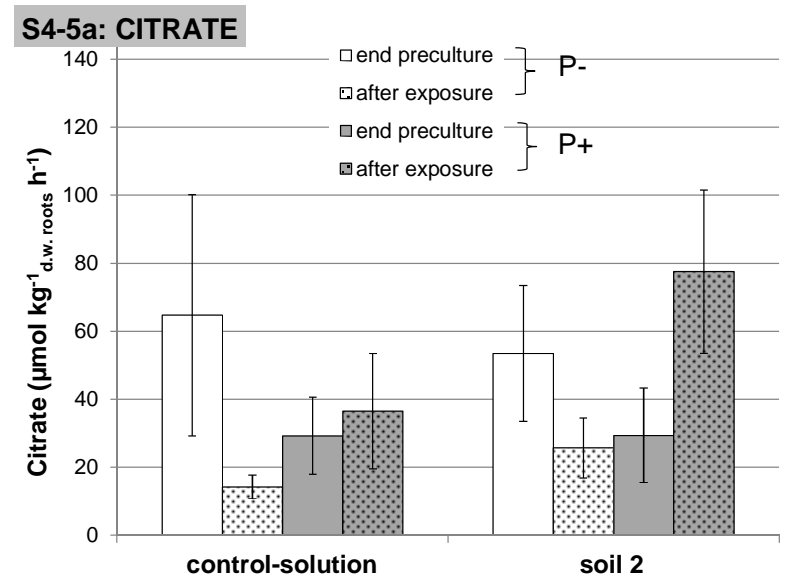



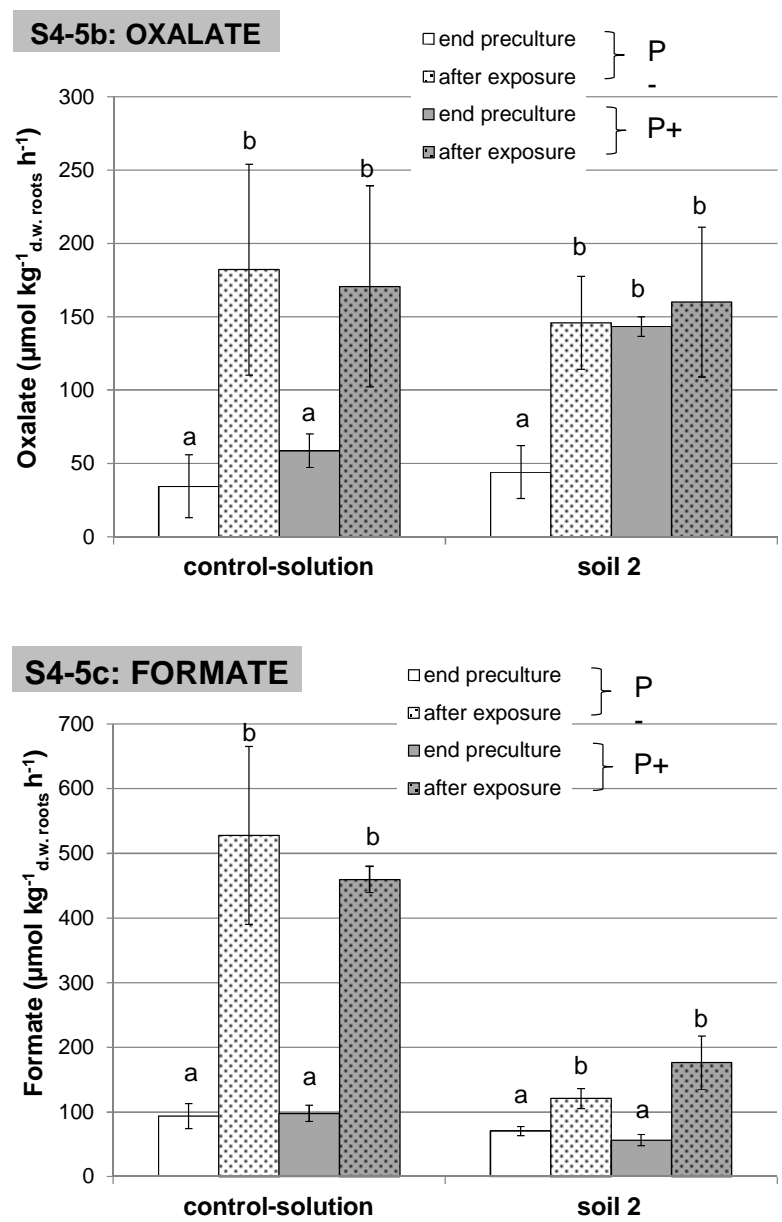

1005 Figure S4-5: Root exudation of citrate (5a), oxalate (5b) and formate (5c) on the rhizotest 1006 design by lupine plants at the end of the pre-culture period (38 days) and after 5 day-exposure 1007 (43 days of growth in total) to soil or solution as control (mean of 5 replicates \pm standard 1008 error $)$. Letters: statistical analysis $(\mathrm{P}<0.05)$.

1009

1010 Main conclusions addressed for soil 1 are valid for soil 2 (Fig S4-5, Fig. S4-6) with the 1011 following differences: in P-, citrate exudation is not enhanced after soil exposure and for 1012 oxalate exudation there is no differences between P conditions (Fig. S4-5). The increase in U 1013 translocation in $\mathrm{P}+$ condition compared to $\mathrm{P}$ - condition is recorded for lower citrate exudation 1014 rates in soil 2 than in soil 1 (Fig. S4-6). 


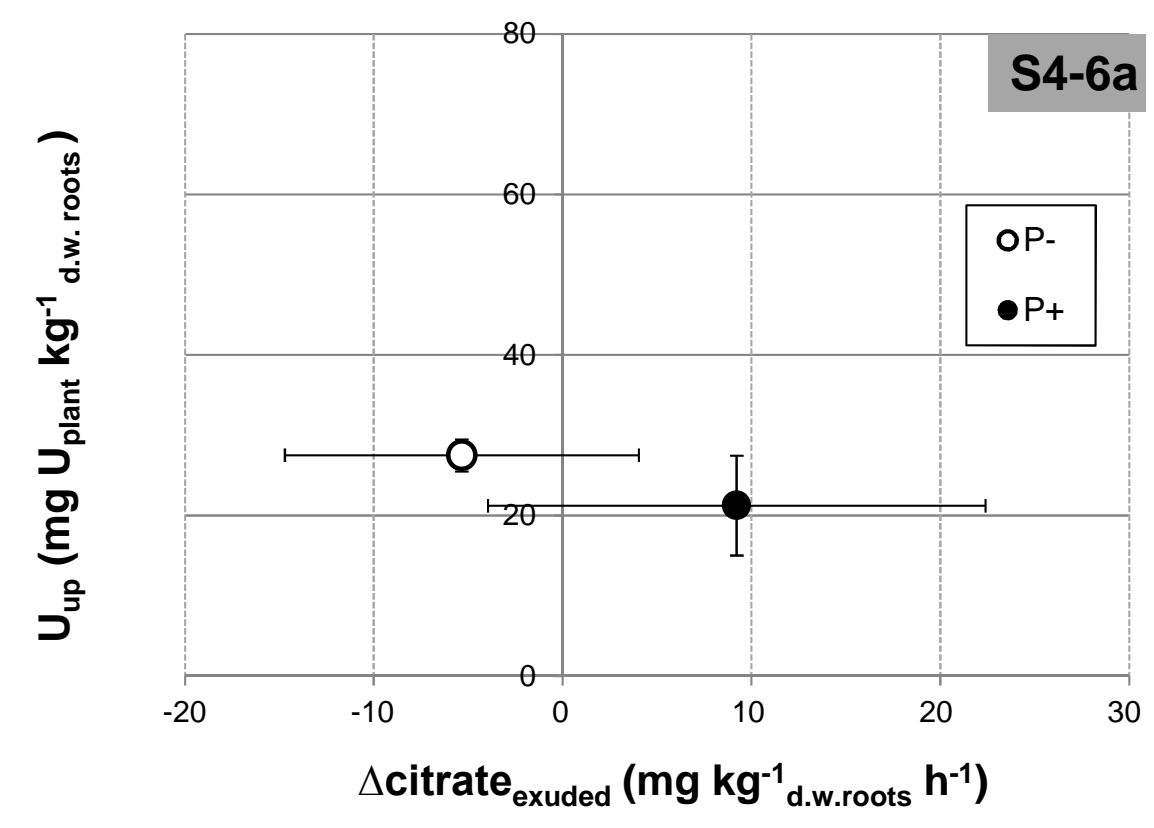

1015

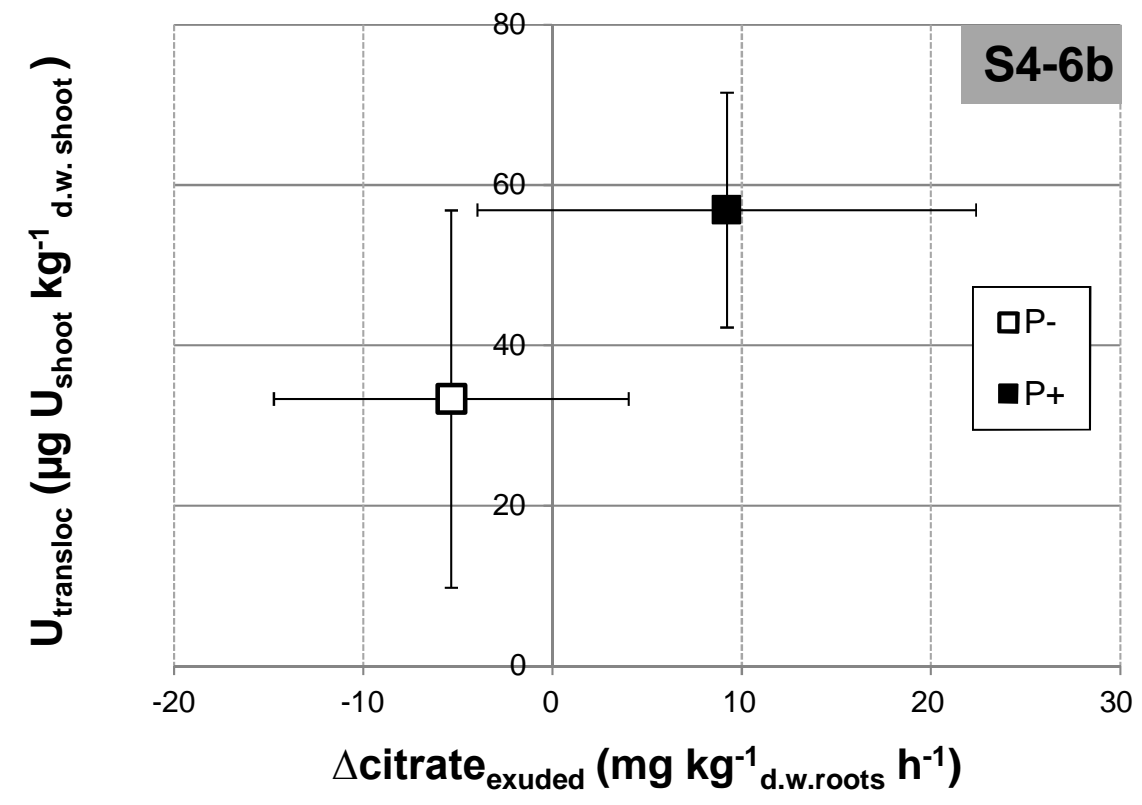

1016

1017 Figure S4-6: Results of U uptake (total $\mathrm{U}$ in plant as related to dry mass of roots, $\mathrm{mg} \mathrm{U}_{\text {plant }} \mathrm{kg}^{-}$ $1018{ }^{1}$ roots d.w., 6a) and $\mathrm{U}$ translocated to shoots $\left(\mu \mathrm{g} \mathrm{U} \mathrm{kg}^{-1}\right.$ shoots d.w., 6b) as a function of $\mathrm{P}$ level and 1019 variation in citrate exudation rate measured between beginning and end of exposure to soil2 1020 ( $\Delta$ citrate $\left._{\text {exuded }}\right)$. Mean of 5 rhizotests \pm s.e.

1021

1022

6. Batch results for soil 2

1023

6.1. Uranium

1024 Results for soil 2, as detailed in the following figures are consistent with conclusions stated 1025 for soil 1 (Fig S4.7, S4-8). 


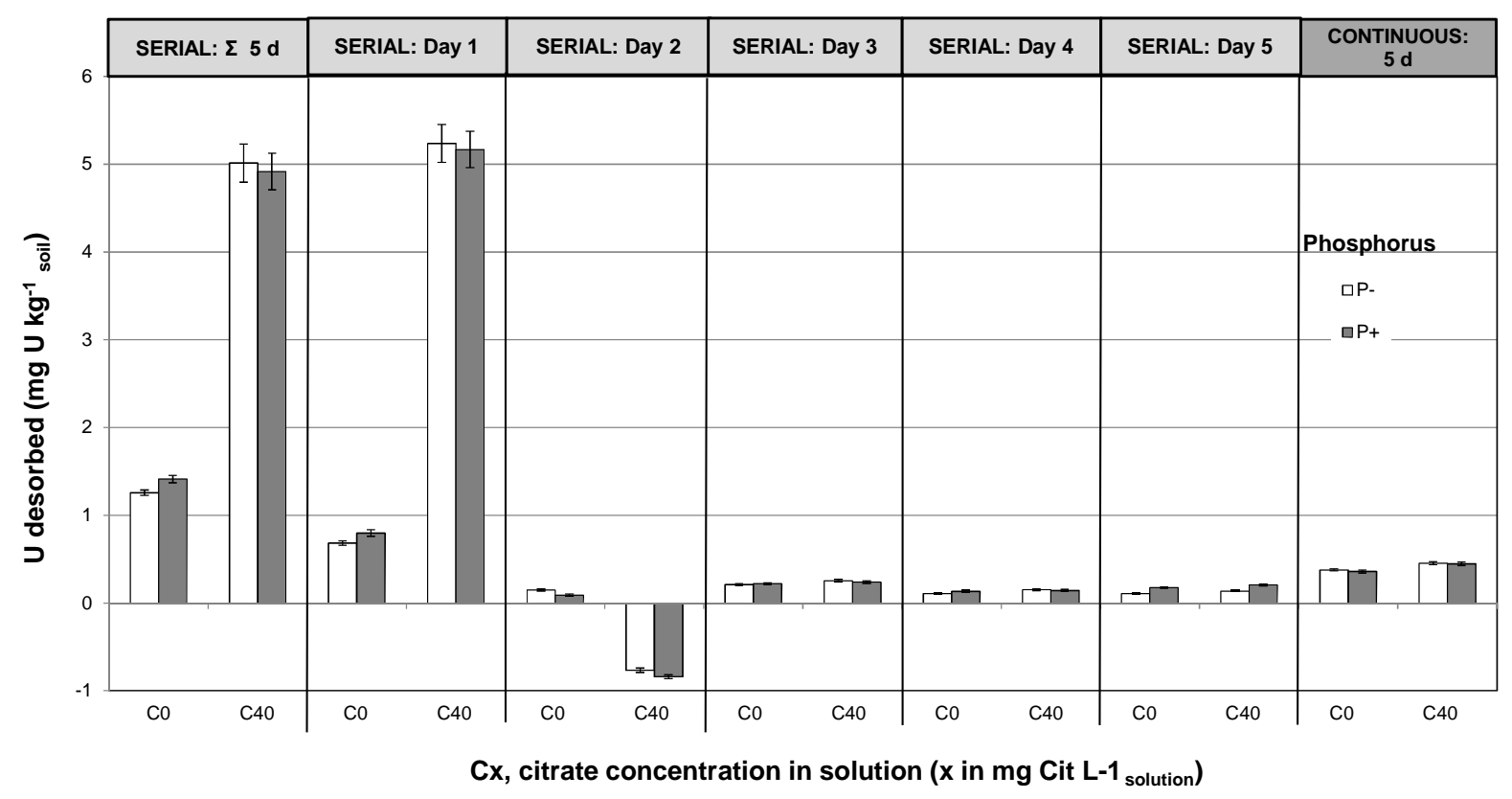

1027 Figure S4-7: U desorbed from soil 1 as a function of time either for a 5-day continuous 1028 extraction, or a 5-day serial extraction (with change of solution every day), P status of the 1029 solution and citrate concentration. Mean of 3 replicates \pm s.e. Letters: ANOVA for each day, $1030 \mathrm{p}<0.01$. Values may be positive (desorption) or negative (apparent sorption).

1031

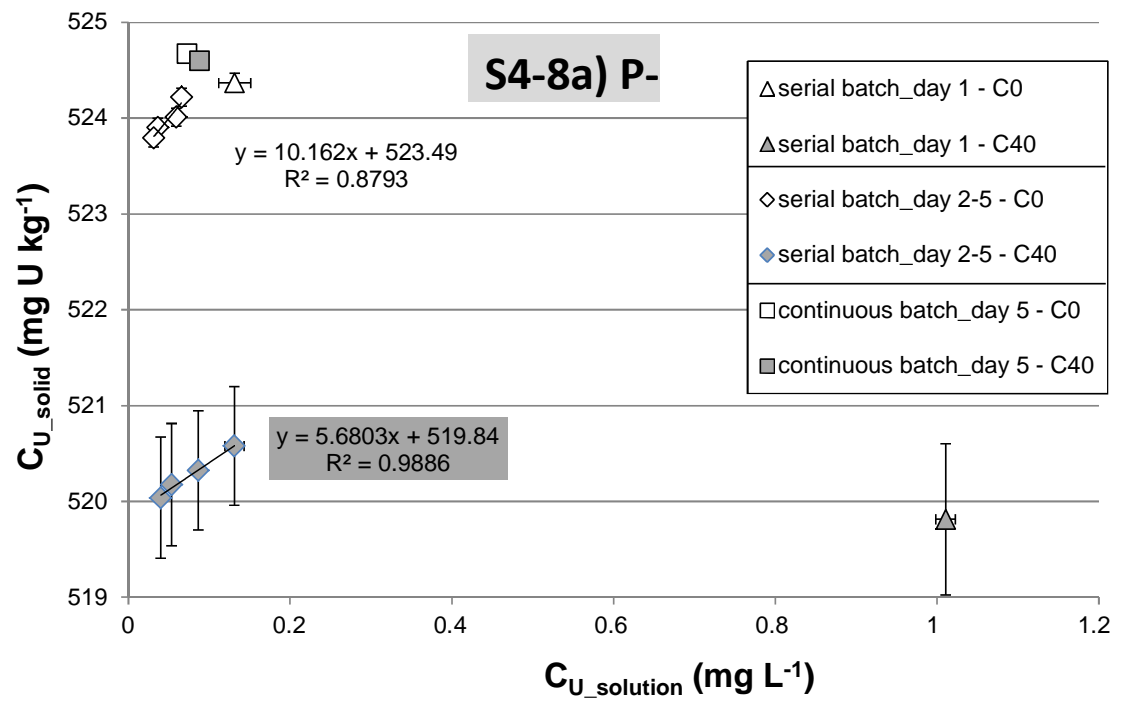




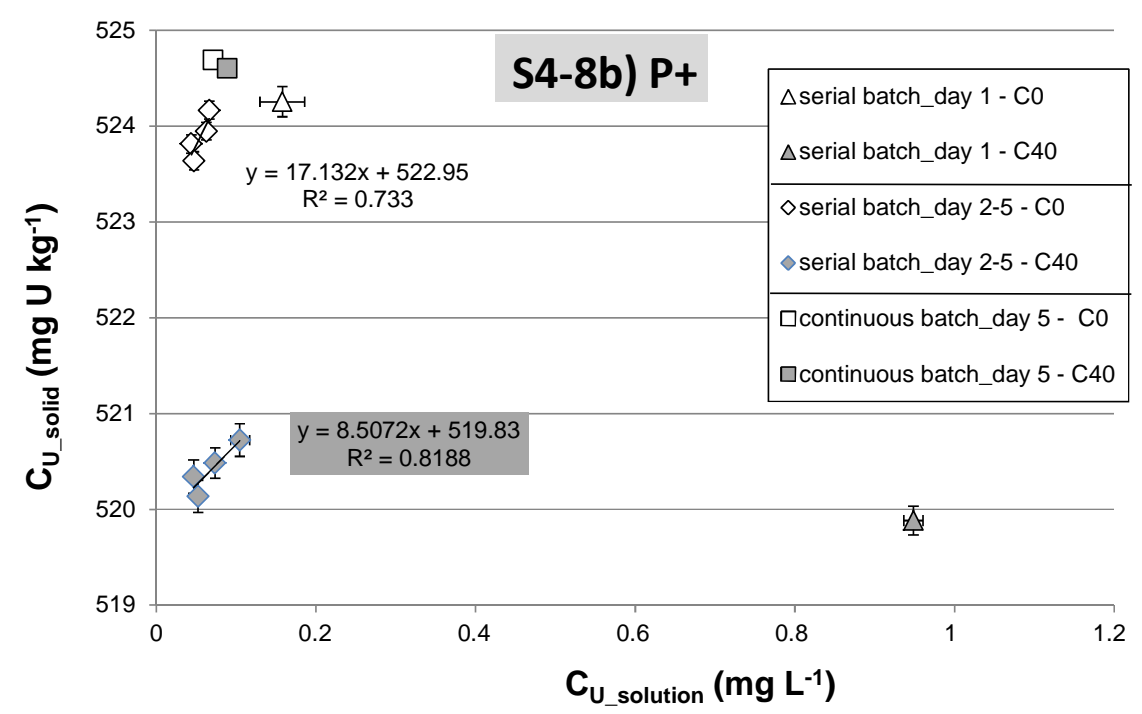

1033

1034 Figure S4-8: Soil 2- $\mathrm{C}_{\mathrm{U}_{-} \text {total_solid }}$ as a function $\mathrm{C}_{\mathrm{U}_{-} \text {solution }}$ at the end of each step of serial vs

1035 continuous batch for the a) P- and b) P+ conditions and all citrate concentrations. Mean of 3

1036 replicates \pm s.e.

1037

1038 In the absence of citrate, the $U$ extractable pool was estimated to be $0.4 \pm 0.1 \%$ of total soil $U$ 1039 as for soil 1 , but the pool in $\mathrm{P}$ - condition $(0.3 \pm 0.1 \%)$ was slightly lower than in $\mathrm{P}+$ condition 1040 (Fig S4-9a.). The size of the extractable pool increased with the high citrate concentration 1041 (C40) up to $0.99 \%$ for soil 2, a value higher than for soil 1 . The extractable pool was easily 1042 accessible as shown by the corresponding low $\mathrm{k}_{\mathrm{d}}$ ' values for all modalities (Fig S4-9b). The 1043 availability (as estimated by the level of U extractability) in soil 2 tended to be lower than in 1044 soil 1, especially with citrate.

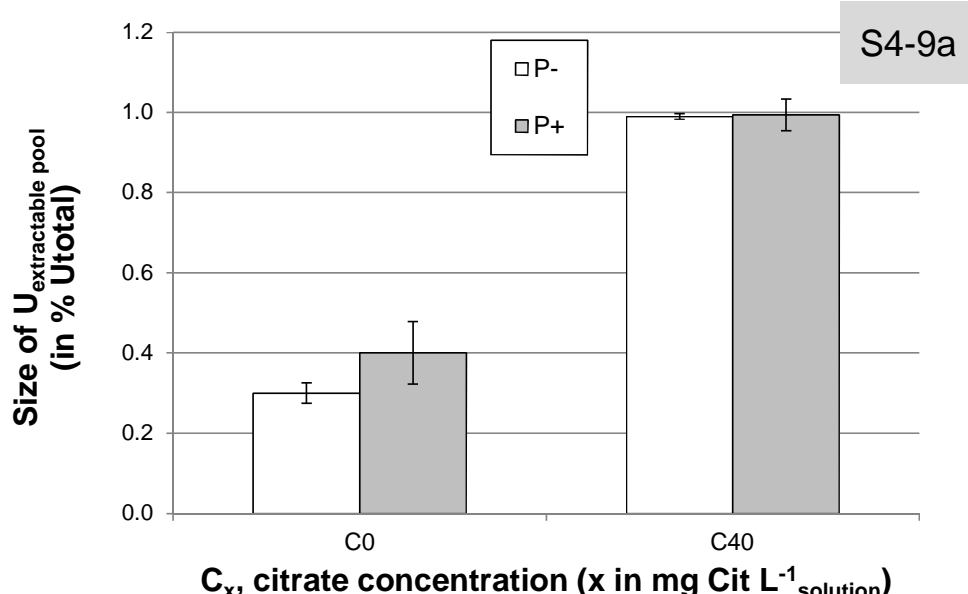




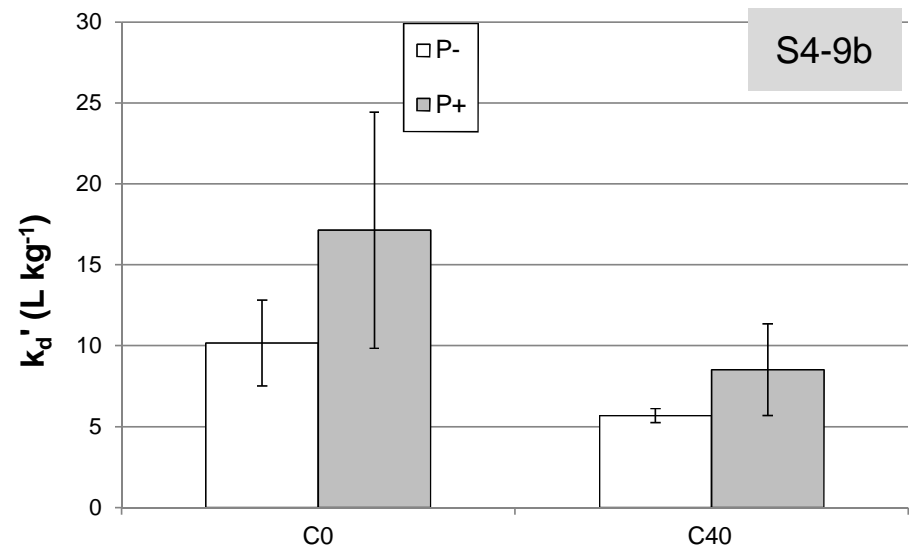

1047 Figure S4-9a-Size of U extractable pool (\% of total soil U) and 9b-k' ${ }_{d}$ ' as a function of soil, P 1048 and citrate conditions (estimate \pm s.e.).

1049

1050

6.2. $\mathrm{Fe}, \mathrm{Ca}, \mathrm{P}$, citrate and oxalate

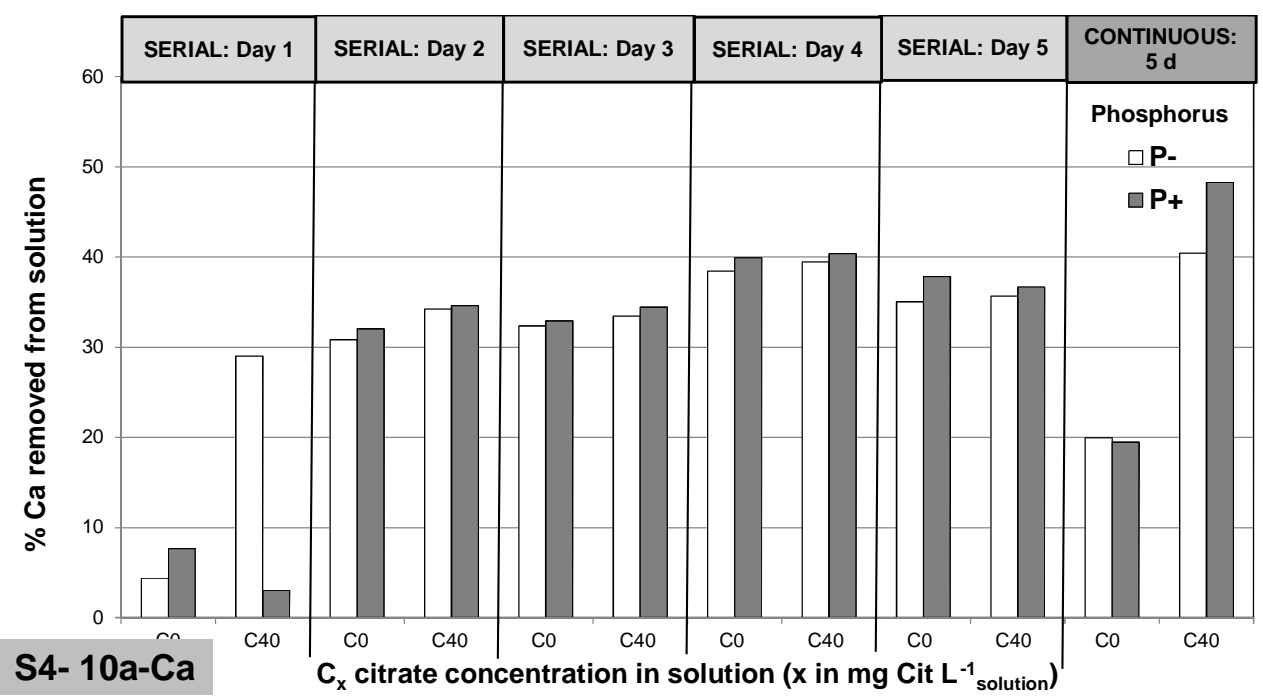



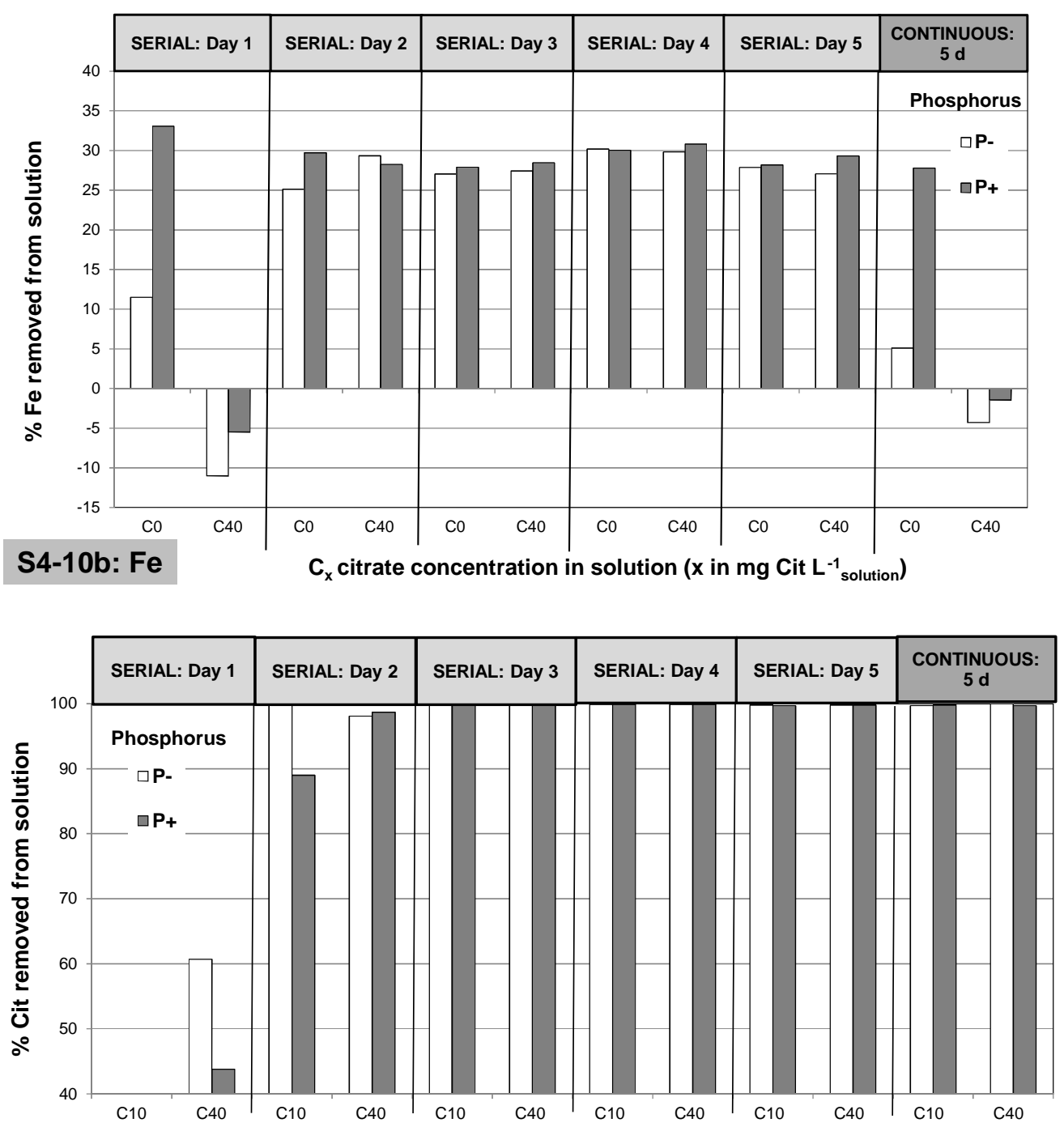

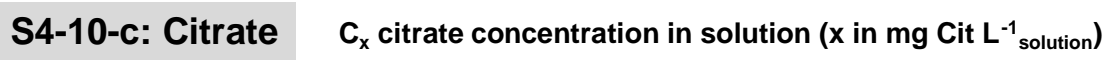

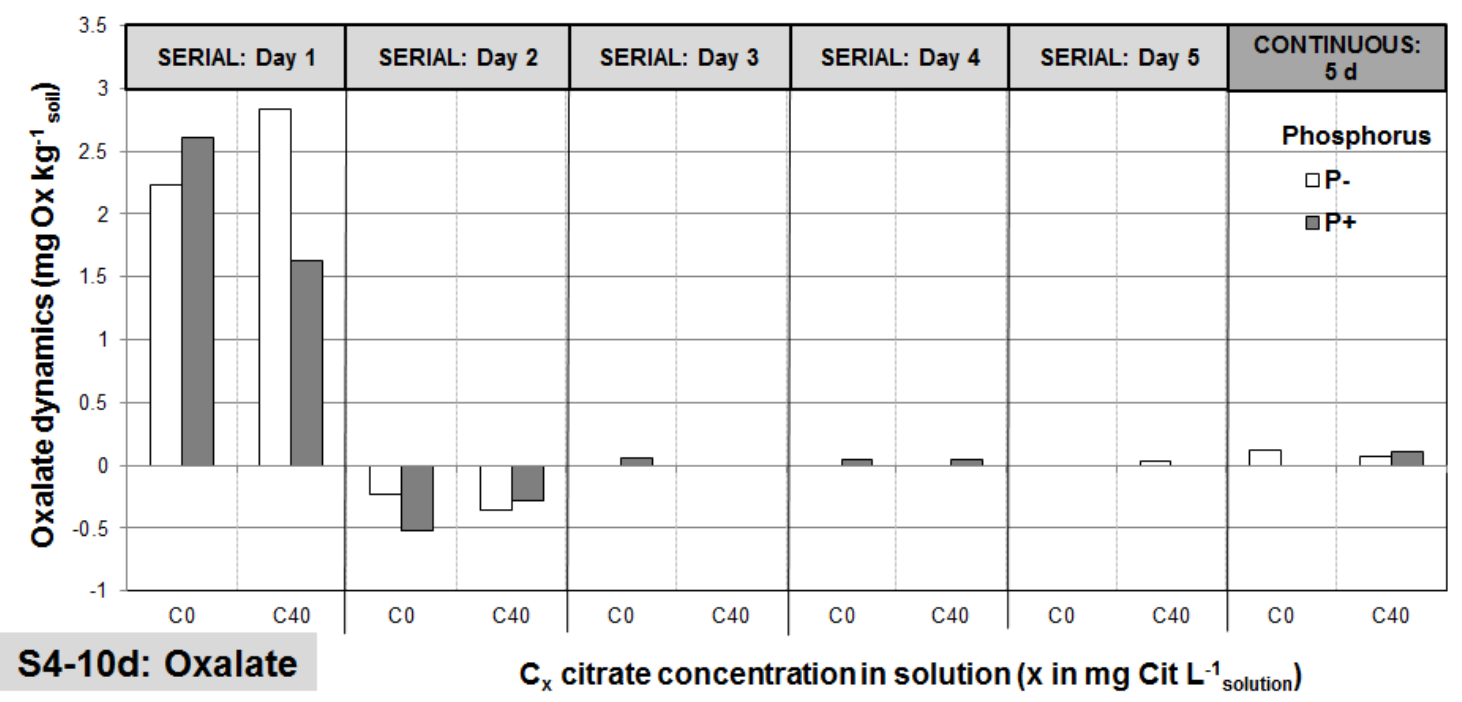

1055 Figure S4-10: Calcium (10a), iron (10b) and citrate (10c) removal from solution and oxalate 1056 release (10d) during each step as a function of citrate concentration in solution (C0/C40 1057 conditions ${ }^{*}$ ), phosphorus status (P- or P+ for 1 and $100 \mu \mathrm{M}$ P respectively) and type of batch 
1058 (serial or continuous). "Contrary to $U$ and Oxalate, Fe, Ca and citrate are present in the 1059 initial solution, thus dynamics was calculated as the difference between final and initial 1060 solution concentration. Values may be positive (decrease compared to initial concentration) 1061 or negative (apparent release) depending which process was dominant during the 1062 corresponding period (24h or 5 days).

1063

1064

1065

1066

1067 